\title{
Numerical modelling of the hydrogeological and geomechanical behaviour of a large slope movement: the Triesenberg landslide (Liechtenstein)
}

\author{
B. François, L. Tacher, Ch. Bonnard, L. Laloui, and V. Triguero
}

\begin{abstract}
Using advanced hydrogeological and geomechanical finite element modelling, it has been possible to model the mechanical behaviour of a large slope movement, the Triesenberg landslide. This slope is located along the Rhine valley in the Principality of Liechtenstein and covers an area of around $5 \mathrm{~km}^{2}$, which includes two villages. Pore-water pressure fields calculated by the hydrogeological model were used as input for the geomechanical model. The results obtained through numerical simulation agree fairly well with field measurements of peak velocity, spatial and temporal distribution of velocity, and total displacements. Such results were obtained using a modified Cam-Clay elastoplastic constitutive model for which the required material parameters were obtained through careful geotechnical tests. These finite element models were carried out in two and three dimensions to gradually improve the understanding of the physical phenomena governing the hydrogeological conditions and the movements of the slope.
\end{abstract}

Key words: landslides, slope movement, hydromechanical coupling, elastoplasticity, numerical modelling.

\begin{abstract}
Résumé : Grâce à une modélisation hydrogéologique et géomécanique par la méthode des éléments finis, il a été possible de modéliser le comportement mécanique d'un grand glissement de terrain, le glissement de Triesenberg. Cette pente en mouvement se développe sur une superficie d'environ $5 \mathrm{~km}^{2}$ le long de la vallée du Rhin dans la principauté du Liechtenstein en incluant deux villages. Les champs de pression interstitielle issus du modèle hydrogéologique ont été utilisés comme données d'entrée pour le modèle géomécanique. Les résultats obtenus grâce aux simulations numériques s'avèrent être assez proches des données recueillies in situ, aussi bien en terme de vitesse en phase de crise que de distributions temporelle et spatiale de ces vitesses ou des déplacements totaux. De tels résultats ont pu être obtenus avec le modèle constitutif élasto-plastique Cam-Clay modifié et des paramètres de matériaux déterminés grâce à des tests géomécaniques rigoureux. Ces modélisations ont été menées en 2 et en 3 dimensions afin d'appréhender et de comprendre de mieux en mieux les phénomènes physiques régissant à la fois les conditions hydrogéologiques et les mouvements de la pente.
\end{abstract}

Mots-clés : glissements de terrain, mouvement de pente, couplage hydromécanique, élastoplasticité, modélisation numérique.

\section{Introduction}

This study concerns the qualitative and quantitative finite element analyses of the movements observed on a slope along the Rhine valley in the Principality of Liechtenstein, located to the east of Switzerland (Fig. 1). The infrastructures related to two important villages (Triesen and Triesenberg) located on this mountainside are subject to sig-

Received 29 March 2006. Accepted 5 March 2007. Published on the NRC Research Press Web site at cgj.nrc.ca on

8 August 2007.

B. François, Ch. Bonnard, L. Laloui, ${ }^{1}$ and V. Triguero. Soil Mechanics Laboratory (LMS), Ecole Polytechnique Fédérale de Lausanne (EPFL), Station 18, CH-1015 Lausanne, Switzerland. L. Tacher. Engineering and Environmental Geology Laboratory (GEOLEP), Ecole Polytechnique Fédérale de Lausanne (EPFL), Station 18, CH-1015 Lausanne, Switzerland.

${ }^{1}$ Corresponding author (e-mail: lyesse.laloui@epfl.ch). nificant damage caused by the movements during critical periods. A hydromechanical model was used to understand the main causes and mechanisms of the phenomenon and predict the behaviour of this slope in critical future conditions. The model included the following steps: (i) three-dimensional (3D) hydrogeological modelling of the slope, (ii) preliminary two-dimensional (2D) geomechanical simulations to calibrate the model parameters and evaluate the effects of some hypotheses on the boundary conditions, and (iii) 3D simulations to improve the understanding of the process and obtain a 3D distribution of the movements.

Many numerical modelling case studies of landslide mechanisms have already been published. The numerical simulation of such problems is particularly convenient to clarify complex mechanisms governing the movements and stability conditions of slopes. Some such complex aspects can be considered, such as strain localizations and the development of shear zones (Dounias et al. 1988; Troncone 2002), viscoelastoplasticity (Desai et al. 1995; Vulliet 2000), 
Fig. 1. Location of the Triesenberg landslide to the east of Switzerland in the Principality of Liechtenstein. Coordinates of the village of Triesenberg are $47^{\circ} 07^{\prime} 08^{\prime \prime} \mathrm{N}$ latitude, $09^{\circ} 32^{\prime} 47^{\prime \prime} \mathrm{E}$ longitude; and $x, y$, and $z$ in the CH1903 Swiss reference system are $759840 \mathrm{~m}$, $220670 \mathrm{~m}$, and $890 \mathrm{~m}$.

(a)

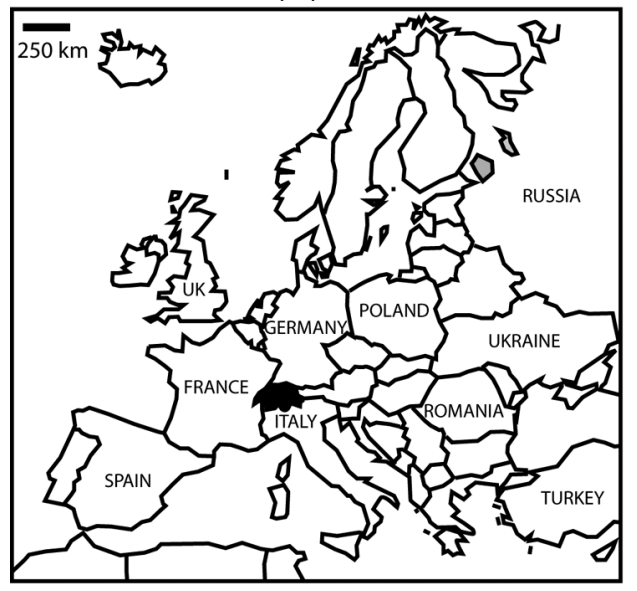

(b)

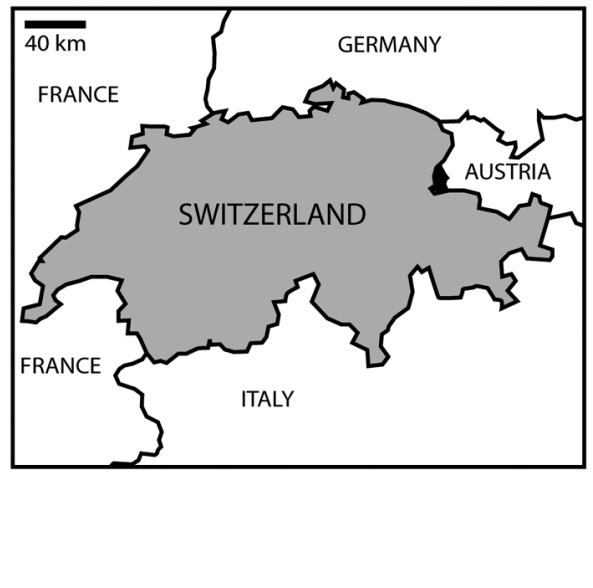

(c)

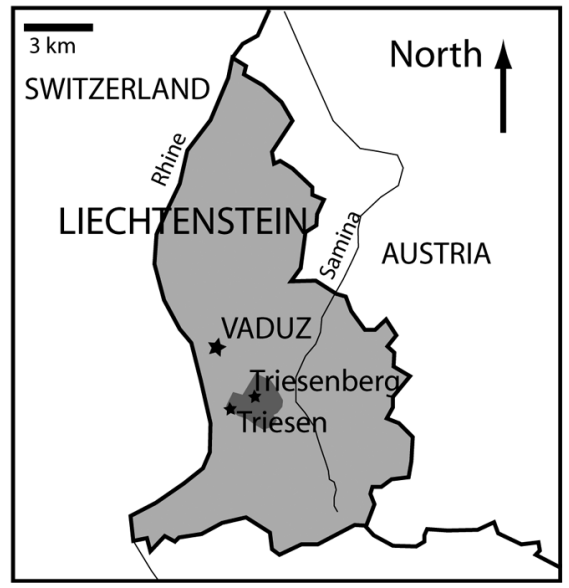

or weathering processes (Eberhardt et al. 2005). However, few studies have been dedicated to the behaviour of very large landslides (i.e., those with a volume greater than 1 million cubic metres and extending over several square kilometres). Among all the numerical studies of instability phenomena, such a coupled hydrogeological and hydromechanical finite element approach has rarely been performed in the past at such a scale and in three dimensions. The major difficulties in modelling the Triesenberg landslide are related to the huge area of the instability, the unsaturated conditions of the slope, and the relatively low velocity of the movements during crises. These different points require a very accurate study of the phenomena to reproduce the real physical behaviour as closely as possible to attain the goals of the study, namely to assess critical hydrogeological conditions, including global climate change impacts and investigate remedial solutions. The same kind of analysis for a large landslide in the Canton of Vaud (Switzerland), namely the La Frasse landslide, was previously carried out (Tacher et al. 2005). A similar methodology was used here.

Several preliminary in situ investigations have been performed. In particular, inclinometer and global positioning system (GPS) data were used to follow the distribution and intensity of the observed movements over time. This information was used to calibrate the numerical models. Moreover, piezometer and flow data were also available. Several soil samples were extracted from different boreholes distributed across the slope, and geotechnical laboratory tests were performed on these samples to assess the mechanical properties of the material forming the slide. These results, like many others presented in this paper, have been compiled in a report delivered to the Liechtenstein authorities (EPFL 2006). Moreover, after the end of the modelling phase, the obtained results can be fortuitously compared with the displacement fields established by interferometry synthetic aperture radar (InSAR) techniques (Colesanti and Wasowski 2004).

The numerical simulations were carried out using the finite element codes Feflow ${ }^{\circledR}$ (version 5.1; Feflow ${ }^{\circledR}$ groundwater modelling software, Wasy AG, Berlin) and Z_SOIL ${ }^{\circledR} 2 \mathrm{D}$ and
3D (version 6.24; Z_SOIL_PC, Zace Services Ltd., Lausanne, Switzerland).

\section{Main features of the landslide}

The study of such large phenomena requires a multidisciplinary approach involving several related conditions (meteorology, topography, geology, hydrogeology, and geotechnical considerations) (DUTI 1985). In that sense, the modelling of the mechanical behaviour was a part of a more global investigation aimed at understanding the observed displacements of the slope, the general features of which are reported in Table 1 (Tullen 2002).

\section{Morphology and geometry}

The topography of the slope has been studied and modelled using a digital terrain model, showing a mean inclination of $24^{\circ}$ and an orientation from northeast (up) to southwest (down). This slope presents some small undulations but is generally quite regular (Fig. 2).

Morphologically, the unstable area can be divided into two main parts. On one hand, in the upper part, a series of deep-seated slope movements occurred in the past, probably when the prehistoric, very deep landslide affecting the whole slope was triggered following glacial retreat. These movements are now underlined by a terrace in the topography at the top of the slope (Fig. 2). This ancient instability area, covering approximately $1.7 \mathrm{~km}^{2}$ with a volume of approximately 74 million cubic metres, is now largely inactive. On the other hand, the active slide takes place on a slip surface located at an average depth of some 10-20 m, whereas the initial prehistoric landslide extended over a depth of more than $80 \mathrm{~m}$ according to the deepest boreholes. The inclinometer data, available from 1995 to 2002, show a very clear, approximately $1 \mathrm{~m}$ thick, slip surface (Fig. 3). Under the slip surface, the bedrock can be assumed to be stable, even though it is formed of prehistoric landslide material (Fig. 2). Indeed, the geodetic measurements agree with the inclinometric data, meaning that there is no displacement of the 
Table 1. General features of the Triesenberg landslide, Principality of Liechtenstein.

\begin{tabular}{ll}
\hline Total area & $\pm 5 \mathrm{~km}^{2}$ \\
Min. elevation & $460 \mathrm{~m}$ asl \\
Max. elevation & $1503 \mathrm{~m}$ asl \\
Total length & $2300 \mathrm{~m}$ \\
Total width & $1500-3200 \mathrm{~m}$ \\
Active slide area & $\pm 3.1 \mathrm{~km}^{2}$ \\
Mean depth & $10-20 \mathrm{~m}$ (active slide) \\
Volume & $\pm 37 \times 10^{6} \mathrm{~m}^{3}$ (active slide) \\
Mean inclination & $24^{\circ}$ \\
Velocity & $0-3 \mathrm{~cm} /$ year \\
Bedrock & Schist, limestone, sandstone, flysch \\
Soil & Elements of limestone, sandstone, dolomite, flysch, and Quaternary deposits \\
& $\quad$ in a clayey silt matrix \\
Vegetation & Pastureland and some wooded zones \\
Methods of investigation & Hydrogeology; boreholes with inclinometers; GPS; radiomagnetotelluric \\
& (RMT) geophysical methods; geotechnical laboratory tests; modelling \\
Possible damage & Infrastructure of two villages \\
\hline
\end{tabular}

Fig. 2. Morphology of the landslide along a longitudinal cross section A-A' (location as shown in Fig. 8). The active slide overlays a prehistoric deeper and older landslide that is currently stabilized (the exact location of the base of this prehistoric instability bottom is uncertain). No vertical exaggeration.

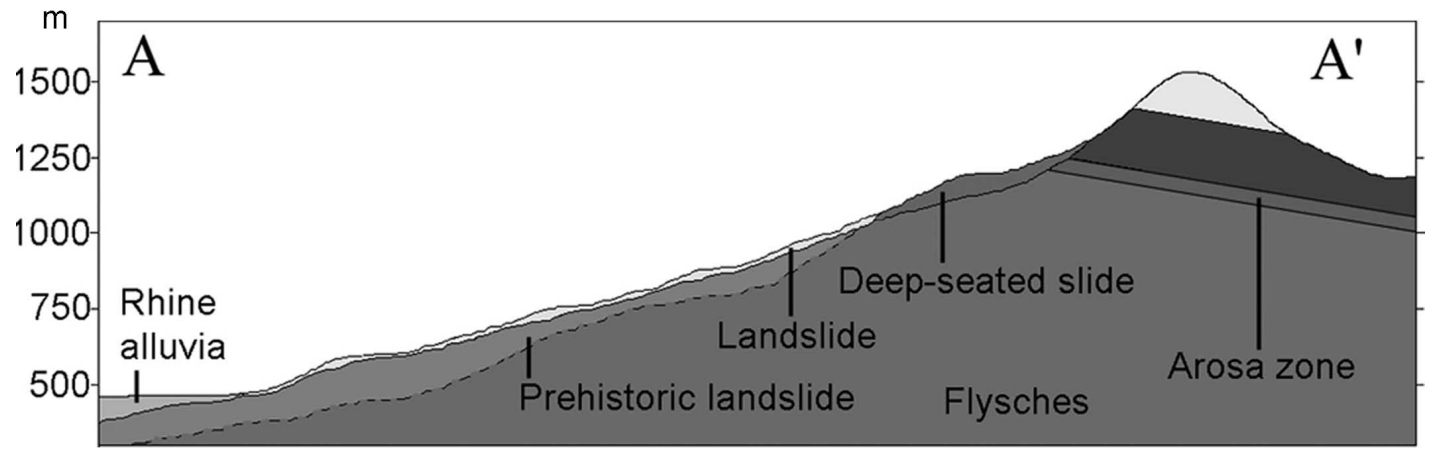

inclinometer bottom. Moreover, no movement has been observed at the toe of the landslide (in the village of Triesen).

The old, deep-seated slope movement zone gradually vanishes at the top of the lower active slide. The influence of the inactive slide zone in the upper part of the slope on the general movement of the lower active slope has been studied by preliminary $2 \mathrm{D}$ modelling (see the section titled Numerical simulation). This led to the conclusion that the old, deepseated slope movement does not represent a driving force causing the instability. This upper zone simply follows the movement of the lower part. The longitudinal profile along the line used for the 2D modelling is shown in Fig. 2.

A preliminary 3D analysis of the intensities and directions of the observed movements (Fig. 4) led to the determination of three quasi-independent instability areas. This assumption can be confirmed by several additional observations:

(1) Three distinct active zones with well-defined limits are present on the slope.

(2) The general shape of the whole instability phenomenon is curved in plan, and the directions of the movement vectors are almost parallel.

(3) The in-depth profile of the slide along a transversal cross section shows three bowl-shaped parts (Fig. 5). The crests in the obvious three bowls should thus corre- spond to the boundaries between each independent slide. This is corroborated by the topographic contour lines presenting similar bulging zones.

(4) The damage to infrastructures and buildings is mainly concentrated along these same boundaries. This could indicate a differential movement phenomenon induced by the displacement decrease on the edge of each instability area.

Whereas the hydrogeological computations concerned the whole area, three different modelling areas were defined for the 3D mechanical modelling (based on the hypothesis of three quasi-independent slides with negligible kinematic interactions). This choice was made to decrease the finite element size of each individual mesh and, therefore, increase the accuracy of the 3D computations.

\section{Hydrogeology}

The hydrogeological analysis and modelling were carried out by the Laboratory of Engineering and Environmental Geology (GEOLEP) of the Ecole Polytechnique Fédérale de Lausanne (EPFL) and Bernasconi Consultant (Sargans, CH), with the aims of $(i)$ understanding the hydrogeological behaviour of the slope, (ii) assessing the effects of climate 
Fig. 3. General trend of inclinometer profiles (inclinometer KL1A; location as shown in Fig. 8; from December 1996 to March 2000).

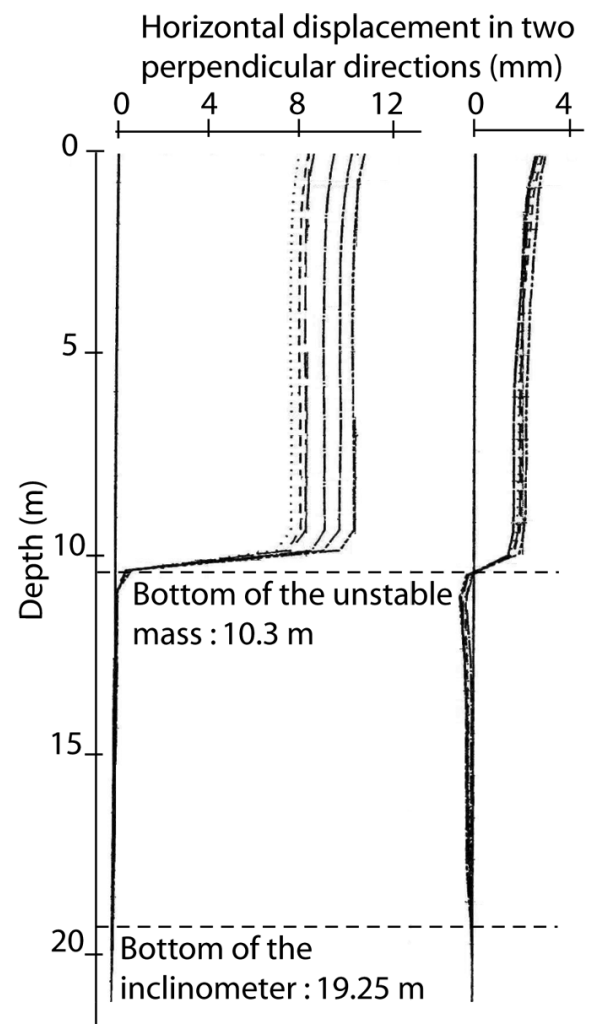

change, and (iii) supplying the geomechanical models with groundwater pressures as daily boundary conditions.

The Triesenberg landslide develops in the Austro-Alpine Triesen flysch (Fig. 6), which is mainly composed of clayey shales. At the top of the slope, the old, deep-seated slide zone is composed of "Buntsandstein" sandstones, shales, and limestones.

Between these two units, the tectonic Arosa zone (Fig. 2) is a very important feature of the hydrogeological system because of its low permeability: part of the Valüna Valley groundwater flows in the Arosa zone and feeds the landslide, causing the Triesenberg groundwater basin to be much larger than its topographic watershed. This assumption is proven by the following three observations:

(1) Tracer tests (Bernasconi 2002a) performed in 1999 in the upper Valüna valley gave positive results in several springs on the landslide.

(2) As the mean elevation of the Valüna valley is higher than that of the Triesenberg slope, snowmelt occurs later and leads to an increase in piezometric head and spring rates in the landslide.

(3) Storm events result in double peaks in piezometric observations in the landslide. After some hours, a first peak occurs and corresponds to the direct infiltration on the slope; some days later, a smoother peak appears and is the inflow from the Valüna valley through the sandstones. Figure 7 shows the hydraulic head in piezometer B4 and the rate of spring Q16, located in Fig. 8, during the 6 August 2000 storm period; at these observation points, the second peak occurred about 10 days after the event.
This double feeding is also effective outside of intensive infiltration periods. Both a hydraulic balance (Bernasconi $2002 b$ ) of the Triesenberg slope and a numerical model calibration (see the section titled Numerical simulation) suggest that about one half of the inflow in the landslide is supplied by the Valüna valley through the sandstones covering the Arosa zone (approx. $9 \times 10^{6} \mathrm{~m}^{3} /$ year).

Groundwater discharge occurs through about 100 springs distributed over the landslide (Fig. 9), as well as at its toe, in the Rhine River alluvia. The water table is located about 20-30 m below the soil surface at the top of the landslide, whereas at the bottom it almost reaches the ground surface. At the top of the slope, the piezometric behaviour is directly influenced by the inflow from the Valüna valley. For example, the hydraulic head in piezometer B4 is rather constant, close to $1101 \mathrm{~m}$, suggesting a base flow due to the capacitive function of the sandstones (see the section titled Numerical simulation). After snowmelt and storm events, however, more than $10 \mathrm{~m}$ high sharp peaks were recorded (Fig. 10). In the lower part of the slide, the inflow peaks from the Arosa zone are smoothed by the landslide aquifer. For example, the piezometric peaks in borehole B8 were less sharp and did not exceed $4 \mathrm{~m}$.

\section{Movements}

The distribution of the surface movements is quite heterogeneous. Inclinometers have been used to measure the intensity of short-term movements locally. An example of inclinometer data in the most active zone is given in Fig. 3. A comparison of coordinates of survey landmarks between old topographic data (1976-1981) and more recent GPS measurements (1996-1997) was carried out to evaluate the medium-term displacements. The distribution of these displacements is shown in Fig. 4. One can observe three different active zones, two at the top and one in the middle of the slope. Moreover, this first investigation on the global medium-term displacement intensity has been confirmed by additional movement monitoring by GPS measurements. This study, completed in 2004 by Frommelt AG, gives the same results in terms of intensity and distribution of the movements.

The yearly observation of displacements shows a close dependence of the movements on the seasons. A reactivation is generally perceived in the spring, which corresponds to the snowmelt period (see the section titled Hypotheses and principle of the geomechanical modelling). This indicates that the main driving force of the movements is the variation of pore-water pressure in the slope.

The estimated range of velocity of the observed movements is given in Table 2 .

\section{Materials}

Several samples of soil were extracted at different locations near the slip surface (but not necessarily within the slip surface zone, as the slip surface could not be precisely located in the boreholes). The major parts of the extracted soil samples have been characterized and identified. These preliminary identifications led to the definition of three main categories of soil with three quite different mechanical properties: ( $i$ ) the loose soil forming the landslide mass, (ii) the slip surface material, and (iii) the bedrock (see the 
Fig. 4. Kinematic and morphological analysis of the slope and division of the instability phenomena into three independent slides.

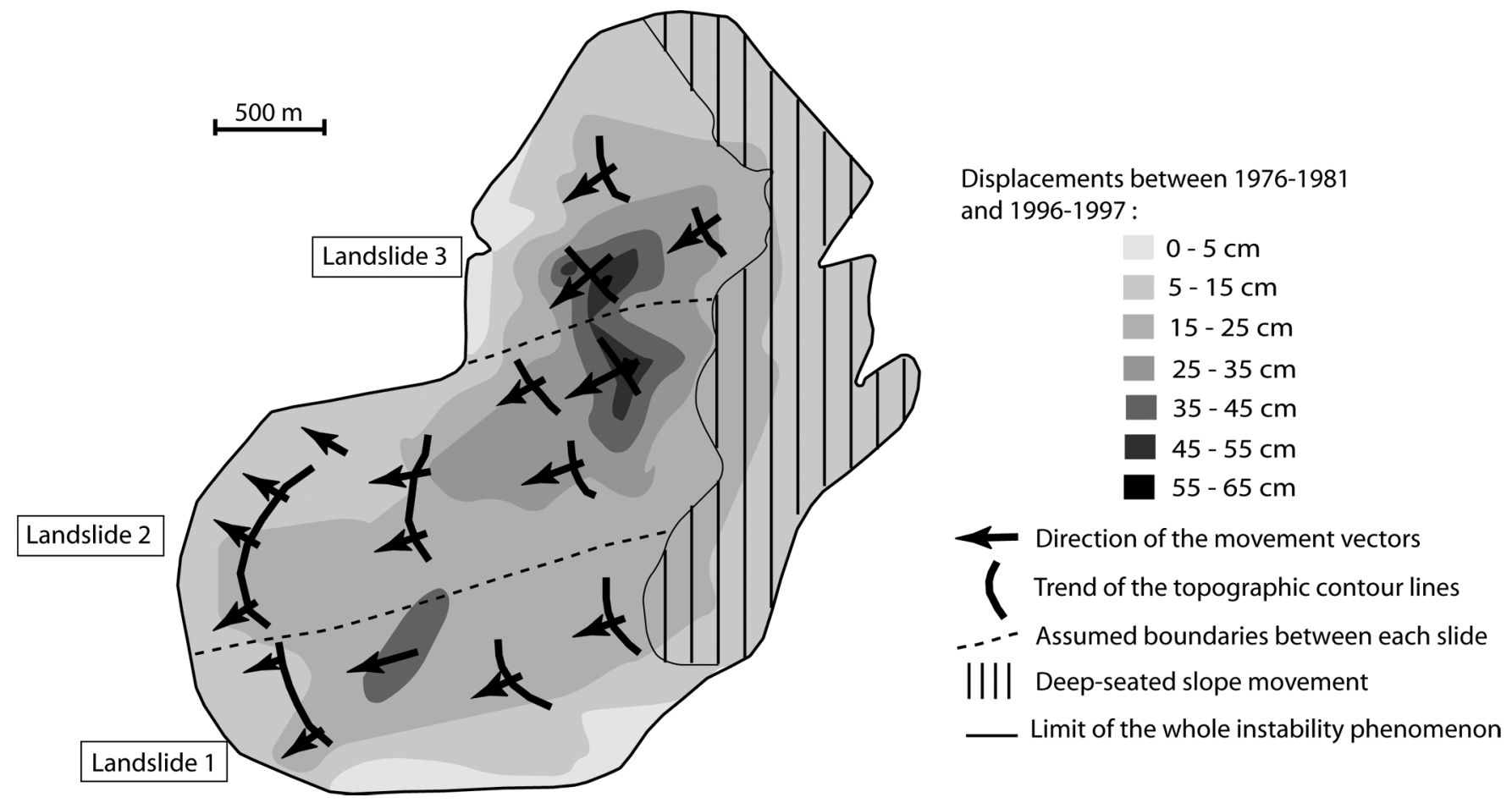

Fig. 5. In-depth variation of the slide along a transversal cross section between the single (*) and double (**) asterisks. Coordinates in the CH1903 Swiss reference system are $759580 \mathrm{~m}, 221880 \mathrm{~m}$, and $1080 \mathrm{~m}$ for the single asterisk and $759580 \mathrm{~m}, 219340 \mathrm{~m}$, and $780 \mathrm{~m}$ for the double asterisk. (Reproduced with permission of swisstopo (BA071481).)

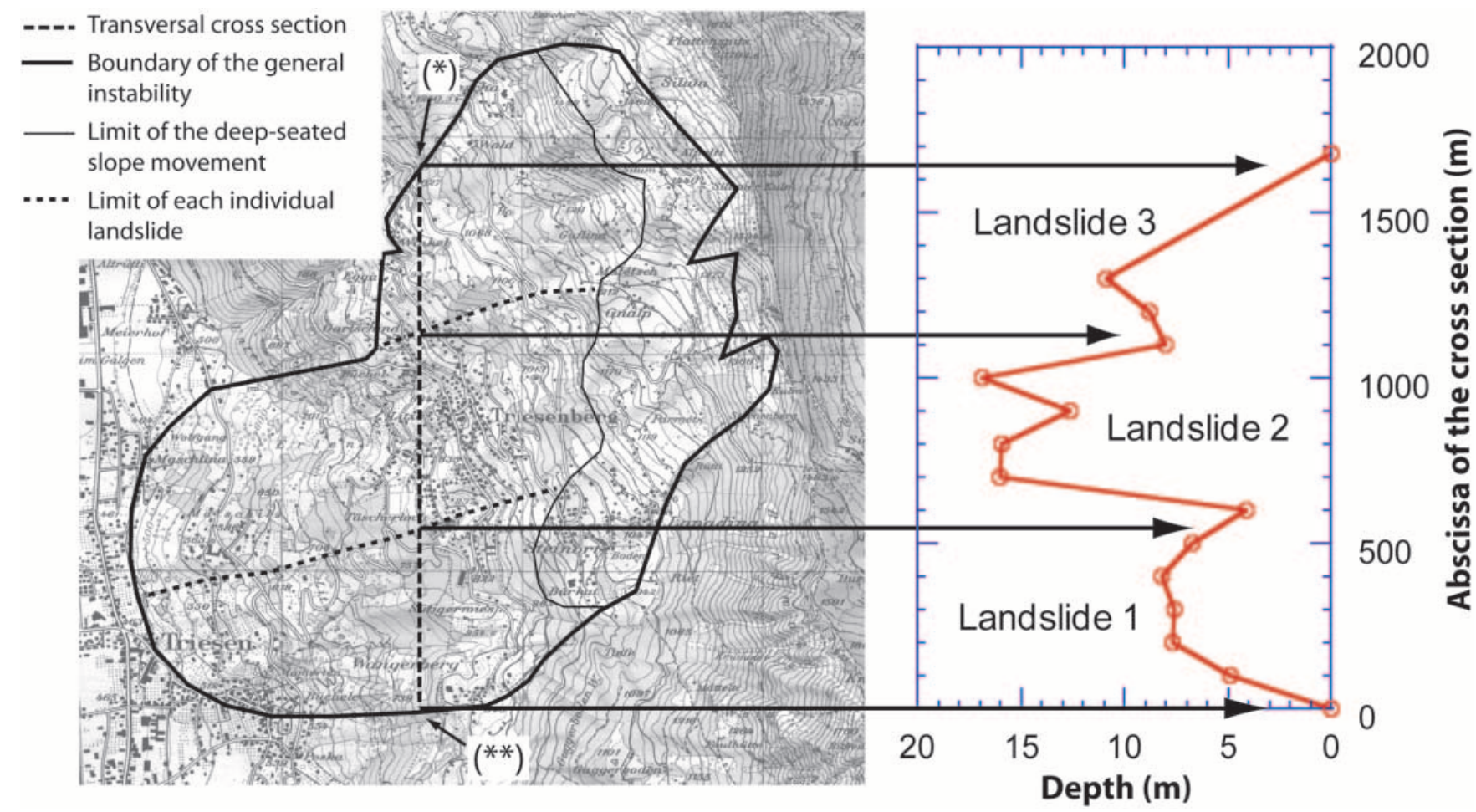

section titled Main features of the landslide). Geotechnical tests (triaxial shear tests under different confining pressures and oedometric compression tests) were carried out on three particular samples, namely samples 5966-1 and 5966-2 extracted from a borehole near the village of Triesen at depths of 12.4 and $21.4 \mathrm{~m}$, respectively, and sample 5966-9 extracted from a borehole at a depth of $28.6 \mathrm{~m}$ in the village of Triesenberg (see the location of the boreholes in Fig. 8). These samples correspond to the three aforementioned soil categories. The tests, carried out at the Soil Mechanics Laboratory (LMS) of EPFL, led to the determination of the material parameters given in Table 3. 
Fig. 6. Geological context of the Triesenberg landslide. The coordinates in the box margins refer to the CH1903 Swiss reference system (in metres).

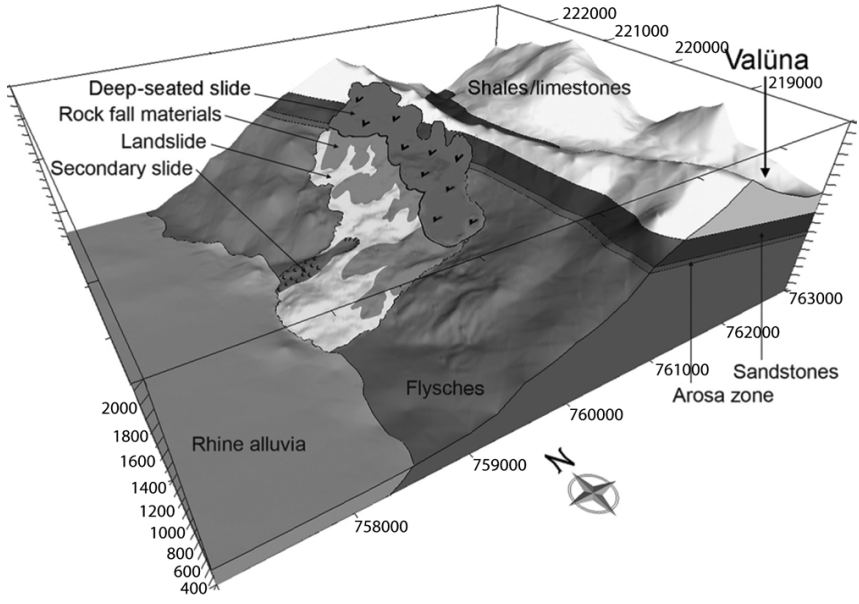

Fig. 7. Daily average hydraulic head in piezometer B4 (right scale) and rate at spring Q16 (left scale) (locations in Fig. 8) in parallel with the total infiltration in the Valüna basin (left scale) during the period of the 6 August 2000 storm. Dates are given as day-month-year.

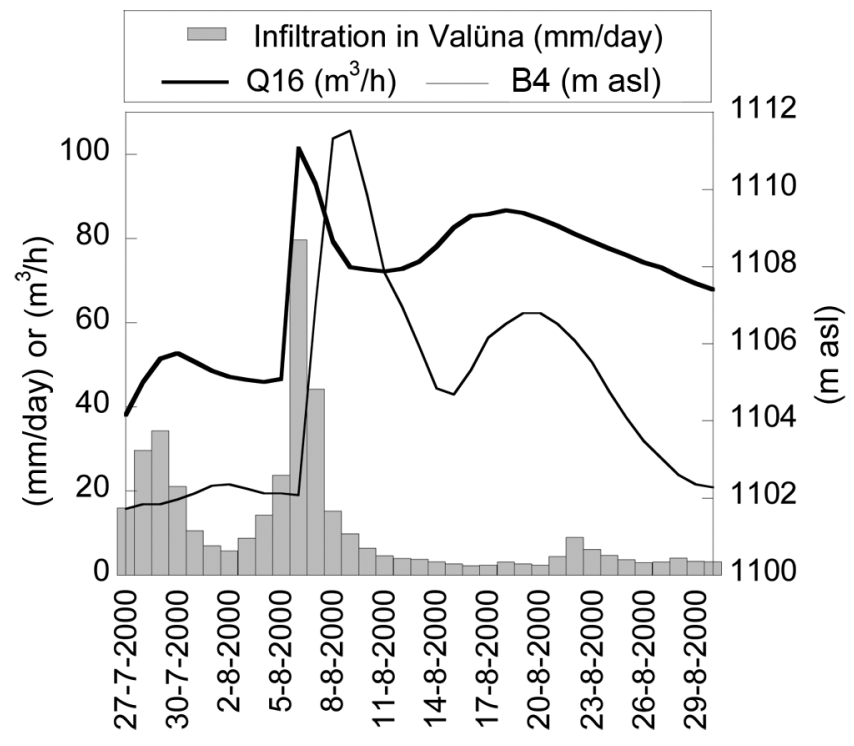

\section{Hypotheses and principle of the geomechanical modelling}

The finite element method was chosen to study the global hydromechanical processes governing the movements and to understand the effects of several parameters on the observed slope displacements. As the pore-water pressure variation in the landslide mass seems to be the main driving force of the movements, a coupled hydromechanical approach was considered.

\section{Mathematical formulation of the hydromechanical coupling}

Due to the relatively low level of the water table at the top of the slope, the landslide takes place in unsaturated conditions over a large part of its longitudinal profile. This observation
Fig. 8. Direction of the cross section used for the $2 \mathrm{D}$ modelling $\left(\mathrm{A}-\mathrm{A}^{\prime}\right)$ and location of several specific points on the slope. Coordinates in the CH1903 Swiss reference system are $758400 \mathrm{~m}$, $219880 \mathrm{~m}$, and $466 \mathrm{~m}$ for the single asterisk and $760720 \mathrm{~m}$, $221410 \mathrm{~m}$, and $1317 \mathrm{~m}$ for the double asterisk. Also shown are the locations of the two inclinometers used for the calibration of the computed displacements (1 and 2), two boreholes from which the tested samples were extracted ( 3 and 4 ), and the two piezometers ( 5 and 6) and the spring (7) used for calibration of the hydrogeological model. (Reproduced with permission of swisstopo (BA071481).)

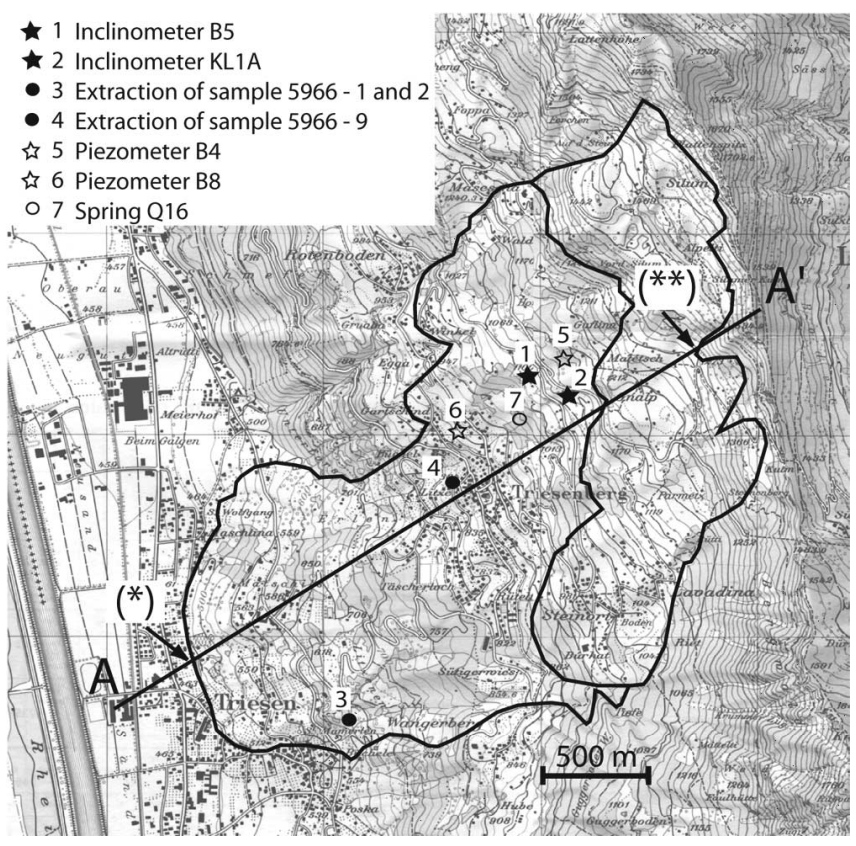

Fig. 9. Boundary conditions at the top $(a)$ and bottom $(b)$ of the model. The open circles denote hydraulic head (with constraints for the springs), and open circles with an arrow denote rate conditions along the Arosa zone.

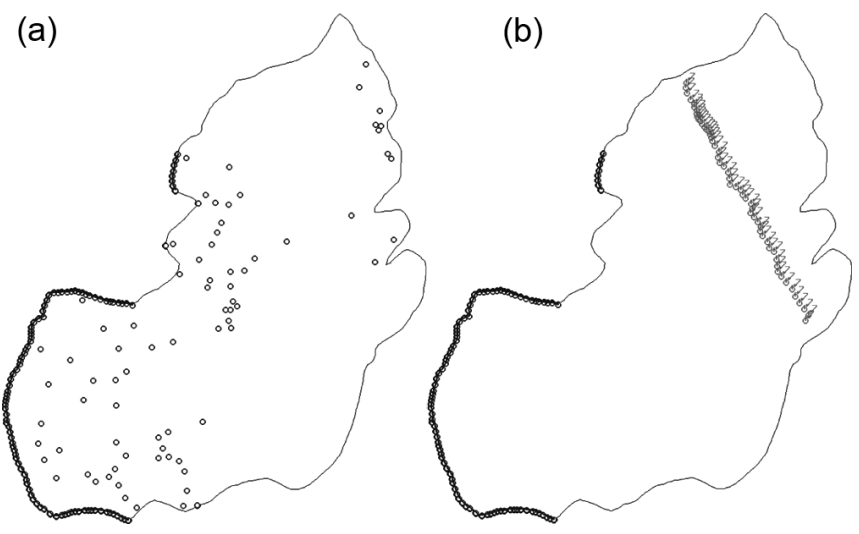

indicates the use of an unsaturated hydromechanical mathematical formulation. The three-phase medium (solid, water, air) was considered as an equivalent two-phase medium with compressible water (it was assumed that the air bubbles were trapped within the liquid phase).

When the soil is considered as a two-phase medium, interactions between the pore-fluid pressure and the mechanical behaviour of the solid skeleton can be obtained with a Biottype mathematical formulation (Biot 1956). In such an ap- 
Fig. 10. Measured hydraulic head in boreholes B4 and B8 in 2000. Dates are given as day-month-year.

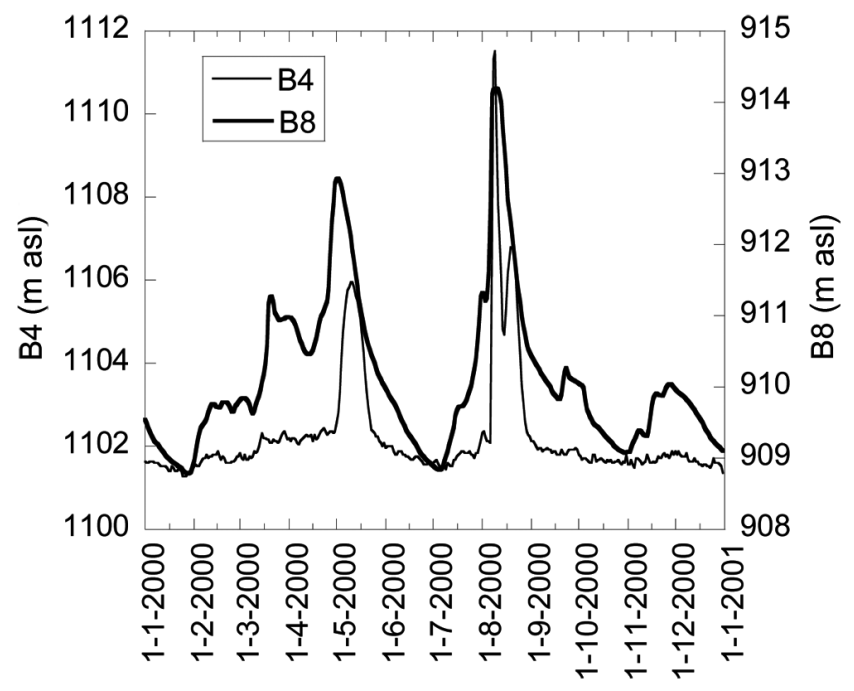

proach, the mass and momentum of the fluid and solid phases are conserved. A thermodynamic description of the general form of the field equations is given in Laloui et al. (2003). The mass conservation equation of the soil is described as follows:

$$
n\left(\beta_{\mathrm{f}} S_{\mathrm{r}}+\frac{\mathrm{d} S_{\mathrm{r}}}{\mathrm{d} p}\right) \partial_{\mathrm{t}} p+\operatorname{div} \partial_{\mathrm{t}} \boldsymbol{u}_{\mathrm{rf}}+S_{\mathrm{r}} \operatorname{div} \partial_{\mathrm{t}} \boldsymbol{u}_{\mathrm{s}}=0
$$

where $p$ is the pore-fluid pressure (compression pressure taken as positive), $\beta_{\mathrm{f}}$ is the water compressibility, $S_{\mathrm{r}}$ is the degree of saturation, and $n$ is the porosity. In this formulation, the solid grains have been assumed to be incompressible, and the skeleton compressibility is expressed by the constitutive law. The velocity vector of the fluid infiltration, $\partial_{\mathrm{t}} \boldsymbol{u}_{\mathrm{rf}}$, links the absolute velocities of the fluid, $\partial_{\mathrm{t}} \boldsymbol{u}_{\mathrm{f}}$, and the solid skeleton, $\partial_{\mathrm{t}} \boldsymbol{u}_{\mathrm{s}}$, by

$$
\partial_{\mathrm{t}} \boldsymbol{u}_{\mathrm{rf}}=n\left(\partial_{\mathrm{t}} \boldsymbol{u}_{\mathrm{f}}-\partial_{\mathrm{t}} \boldsymbol{u}_{\mathrm{s}}\right)
$$

Darcy's law is then introduced to link the infiltration velocity with the hydraulic head:

$$
\partial_{\mathrm{t}} \boldsymbol{u}_{\mathrm{rf}}=-\boldsymbol{K}^{*} \operatorname{grad}\left(p+\rho_{\mathrm{f}} \boldsymbol{g} \boldsymbol{x}\right)
$$

where $\rho_{\mathrm{f}}$ is the volumetric mass of the fluid (water), $\boldsymbol{g}$ is the vector of the acceleration due to gravity, $\boldsymbol{x}$ is the position vector, and $\boldsymbol{K}^{*}$ is the tensor of the kinematic soil permeability. $K^{*}$ is a function of the degree of saturation $S_{\mathrm{r}}$ and is obtained by multiplication of the tensor of the saturated permeability $\boldsymbol{K}$ by a scalar function, $k_{\mathrm{r}}\left(S_{\mathrm{r}}\right)$ (Van Genuchten 1980):

$$
\left\{\begin{array}{l}
\boldsymbol{K}^{*}=k_{\mathrm{r}} \boldsymbol{K} \\
k_{\mathrm{r}}=\frac{\left(S_{\mathrm{r}}-S_{\mathrm{r}, \mathrm{res}}\right)^{3}}{\left(1-S_{\mathrm{r}, \mathrm{res}}\right)^{3}}
\end{array}\right.
$$

where $S_{\mathrm{r}, \mathrm{res}}$ is the residual degree of saturation. The degree of saturation is related to the pore-fluid pressure by the following expression (Van Genuchten 1980):
Table 2. Order of magnitude of the observed velocity of the landslide movements.

\begin{tabular}{lll}
\hline Term & Period & Velocity $(\mathrm{cm} /$ year $)$ \\
\hline Medium & $>20$ years & $0.5-3.0$ \\
Short & \pm 1 year & $0.1-4.0$ \\
Exceptional & $<1$ month & Up to 6.0 \\
\hline
\end{tabular}

[5]

$$
\begin{cases}S_{\mathrm{r}}=S_{\mathrm{r}, \mathrm{res}}+\frac{1-S_{\mathrm{r}, \mathrm{res}}}{\left[1+\left(\alpha \frac{p}{\rho_{\mathrm{f}} g}\right)^{2}\right]^{1 / 2}} & \text { if } p<0 \\ S_{\mathrm{r}}=1 & \text { if } p \geq 0\end{cases}
$$

where $\alpha$ is a material parameter. Thus, the mass conservation is expressed by

$$
\begin{aligned}
S_{\mathrm{r}} \operatorname{div} \partial_{\mathrm{t}} \boldsymbol{u}_{\mathrm{s}}=\operatorname{div}\left[\boldsymbol{K}^{*} \operatorname{grad}\left(p+\rho_{\mathrm{f}} \boldsymbol{g} \boldsymbol{x}\right)\right] & \\
& -n\left(\beta_{\mathrm{f}} S_{\mathrm{r}}+\frac{\mathrm{d} S_{\mathrm{r}}}{\mathrm{d} p}\right) \partial_{\mathrm{t}} p
\end{aligned}
$$

As can be seen, the temporal variation of the solid displacement (term on the left side) can be modified even by Darcy's flow (first term on the right side) and (or) by the pore-fluid pressure variation (second term on the right side).

The soil equilibrium equation is given by

[7] $\operatorname{div} \boldsymbol{\sigma}-\rho g=0$

where $\sigma$ is the total (Cauchy) stress tensor, with compression stresses taken as positive; and $\rho$ is the total average mass density $\left(\rho=\rho_{d}+n S_{r} \rho_{f}\right.$, where $\rho_{d}$ is the mass density of the solid skeleton). The divergence operator is defined as

$$
\{\operatorname{div} \sigma\}_{i j}=\sum_{i j} \partial_{j} \sigma_{i j} \quad(i, j=1,3)
$$

The behaviour of the solid matrix is assumed to be governed by the generalized Bishop's effective stress equation (Schrefler 1984; Laloui and Nuth 2005) given by

[9] $\boldsymbol{\sigma}^{\prime}=\boldsymbol{\sigma}-S_{\mathrm{r}} p \delta$

where $\boldsymbol{\sigma}^{\prime}$ is the effective stress tensor, and $\delta$ is the Kroenecker's symbol. In the small-strain approach adopted here (justified in the section titled Numerical simulation), the effective stress tensor can be expressed in terms of the total strain tensor $\boldsymbol{\varepsilon}$ and the elastoplastic constitutive tensor $\boldsymbol{C}$, the total strain tensor being related to the total displacement tensor of a solid skeleton $\boldsymbol{u}_{\mathrm{s}}$ by the following expression:

$$
\text { [10] } \boldsymbol{\varepsilon}=\left(\boldsymbol{u}_{\mathrm{s}}+\boldsymbol{u}_{\mathrm{s}}^{\mathrm{T}}\right) / 2
$$

where the superscript $\mathrm{T}$ expresses the transposition of the tensor. Thus, the momentum conservation equation takes the following form:

$$
\operatorname{div}\left\{\boldsymbol{C}: \boldsymbol{\varepsilon}\left(\boldsymbol{u}_{\mathrm{s}}\right)\right\}=\rho \boldsymbol{g}-S_{\mathrm{r}} \operatorname{grad} p
$$

Equations [6] and [11] then compose the two field equations with two unknowns $\left(\boldsymbol{u}_{\mathrm{s}}, p\right)$. 
Table 3. Properties of the three intact samples tested in the laboratory.

\begin{tabular}{|c|c|c|c|c|c|c|c|c|}
\hline \multirow[b]{2}{*}{ Sample No. } & \multicolumn{4}{|c|}{ Physical properties } & \multicolumn{4}{|c|}{ Mechanical properties } \\
\hline & $\begin{array}{l}\text { Liquid limit } \\
(\%)\end{array}$ & $\begin{array}{l}\text { Plasticity } \\
\text { index }(\%)\end{array}$ & $\begin{array}{l}\text { Fine particles, } \\
<0.02 \mathrm{~mm}(\%)\end{array}$ & $\begin{array}{l}\text { Classification } \\
\text { (USCS) }\end{array}$ & $\begin{array}{l}\text { Young's } \\
\text { modulus } \\
(\mathrm{MPa})\end{array}$ & $\begin{array}{l}\text { Corresponding } \\
\text { confining } \\
\text { pressure }(\mathrm{kPa})\end{array}$ & $\begin{array}{l}\text { Peak friction } \\
\text { angle }\left(^{\circ}\right)\end{array}$ & $\begin{array}{l}\text { Cohesion } \\
(\mathrm{kPa})\end{array}$ \\
\hline \multirow[t]{3}{*}{$5966-1$} & 26.0 & 13.1 & 50.0 & Clay (CL) & 97 & 300 & 25 & 0 \\
\hline & & & & & 134 & 500 & & \\
\hline & & & & & 223 & 800 & & \\
\hline \multirow[t]{3}{*}{$5966-9$} & nd & nd & nd & $\begin{array}{l}\text { Clayey sand } \\
\text { (SC) }\end{array}$ & 276 & 300 & 30 & 17 \\
\hline & & & & & 330 & 500 & & \\
\hline & & & & & 415 & 800 & & \\
\hline
\end{tabular}

Note: The Young's modulus was determined in unloading conditions starting from $2 \%$ of axial strain under a confining pressure noted in the adjacent column. nd, not determined; USCS, Unified soil classification system.

\section{Constitutive law for the soil}

The trends of the inclinometers located at different places in the slope show a coherent movement of the loose soil without large strains within the moving mass. All the strains are concentrated along the slip surface (Fig. 3). This observation leads to the simultaneous consideration of two soil behavioural laws: a nondeformable model (represented by an elastic model with high rigidities) for the loose soil, and a modified Cam-Clay elastoplastic model (Roscoe and Burland 1968) for the material composing the slip surface. The suction effect (negative pore pressure) on the mechanical behaviour is considered through the conservation equations (eqs. [6] and [11]) and the constitutive law for the fluid phase (eqs. [3] and [4]), as well as by the degree of saturation. However, no explicit effect is considered in the solid constitutive law.

The modified Cam-Clay model incorporates the influence of confinement and stress path on the moduli, the consideration of the effects of overconsolidation, and the influence of the void ratio on behaviour (consideration of the critical state and dilatancy) (Schofield and Worth 1968). It describes the soil behaviour using nonlinear elasticity and one plastification mechanism under monotonic deviatoric and isotropic paths. The activation of the plastic mechanism causes a hardening of the material and creates irreversible volumetric strain, $\varepsilon_{\mathrm{v}}^{\mathrm{p}}$. The plastic strain rate is defined through a plastic, associated flow rule.

\section{Elastoplastic formulations}

The elastoplastic framework enables the decomposition of the total strain rate $\dot{\varepsilon}$ into two independent parts, one elastic $\dot{\varepsilon}^{\mathrm{e}}$, and one plastic $\dot{\varepsilon}^{\mathrm{p}}$ :

$$
\dot{\varepsilon}=\dot{\varepsilon}^{\mathrm{e}}+\dot{\varepsilon}^{\mathrm{p}}
$$

The elastic strain increment is obtained through the elastic stiffness tensor $\boldsymbol{D}$ with the bulk modulus $(K)$ and the shear modulus $(G)$ depending on the stress level (nonlinear elasticity):

$$
\left\{\begin{array}{l}
\dot{\varepsilon}^{\mathrm{e}}=\boldsymbol{D}^{-1} \dot{\boldsymbol{\sigma}}^{\prime} \\
K=\frac{1+e_{0}}{\kappa} p^{\prime} \quad \text { and } \quad \frac{G}{K}=\frac{3}{2} \frac{1-2 v}{1+v}=\text { constant }
\end{array}\right.
$$

where $p^{\prime}$ is the mean effective stress, $e_{0}$ is the initial void ratio, $\kappa$ is the slope of the swelling line in the $\left(\ln p^{\prime}, e\right)$ plane, and $v$ is the Poisson's ratio.

Plastic strains are only produced when the stress state reaches the yield limit described by the following equation in the $\left(p^{\prime}, q\right)$ plane:

$$
f\left(p^{\prime}, q, p_{\mathrm{c}}^{\prime}\right)=q^{2}+M^{2} r^{2} p^{\prime}\left(p^{\prime}-p_{\mathrm{c}}^{\prime}\right)=0
$$

where $q$ is the deviatoric stress, $M$ is the slope of the critical state line in the $\left(p^{\prime}, q\right)$ plane, $p_{\mathrm{c}}^{\prime}$ is the preconsolidation pressure, and $r$ is a function of Lode's parameter $\theta$, which enables the extension of the elliptic function in the $\left(p^{\prime}, q\right)$ plane in the principal stress space by a rotation of this yield curve around the $p^{\prime}$ axis according to Van Eekelen (1980).

The initial mechanical state of the material is defined by the overconsolidation ratio (OCR), which is equal to the ratio of the preconsolidation pressure to the initial mean effective stress.

The plastic flow rule is given by

$$
\dot{\varepsilon}^{\mathrm{p}}=\Lambda \partial_{\sigma^{\prime}} f
$$

where $\Lambda\left(\sigma^{\prime}, \varepsilon_{\mathrm{v}}^{\mathrm{p}}\right)$ is the plastic multiplier, and $\varepsilon_{\mathrm{v}}^{\mathrm{p}}$ is the hardening parameter (modifying the yield surface $f\left(\sigma^{\prime}, \varepsilon_{\mathrm{v}}^{\mathrm{p}}\right)$.

Along an isotropic compression path, when the yield limit is reached, the preconsolidation pressure $p_{\mathrm{c}}^{\prime}$ evolves according to the following equation:

$$
\dot{p}_{\mathrm{c}}^{\prime}=-\frac{1+e_{0}}{\lambda-\kappa} p_{\mathrm{c}}^{\prime} \dot{\varepsilon}_{\mathrm{v}}^{\mathrm{p}} \quad \Rightarrow \quad \ln \frac{p_{\mathrm{c}}^{\prime}}{p_{\mathrm{c} 0}^{\prime}}=\frac{1+e_{0}}{\lambda-\kappa} \varepsilon_{\mathrm{v}}^{\mathrm{p}}
$$

where $\lambda$ is the slope of the virgin consolidation line in the (ln $\left.p^{\prime}, e\right)$ plane, $\dot{\varepsilon}_{\mathrm{v}}^{\mathrm{p}}$ is the increment of plastic volumetric strain, and $p_{c 0}^{\prime}$ is the initial preconsolidation pressure.

These mathematical and constitutive formulations were applied using the software Z_SOIL ${ }^{\circledR}$.

\section{Hydromechanical material parameters}

Triaxial shear and oedometric laboratory tests carried out on sample 5966-1 (Figs. 11, 12) were used to determine the necessary mechanical properties of the slip surface material. These are presented in Table 4. The samples were seen to 
Fig. 11. Comparison of the results of triaxial shear test simulations (lines) and the experimental points for three confining pressures.

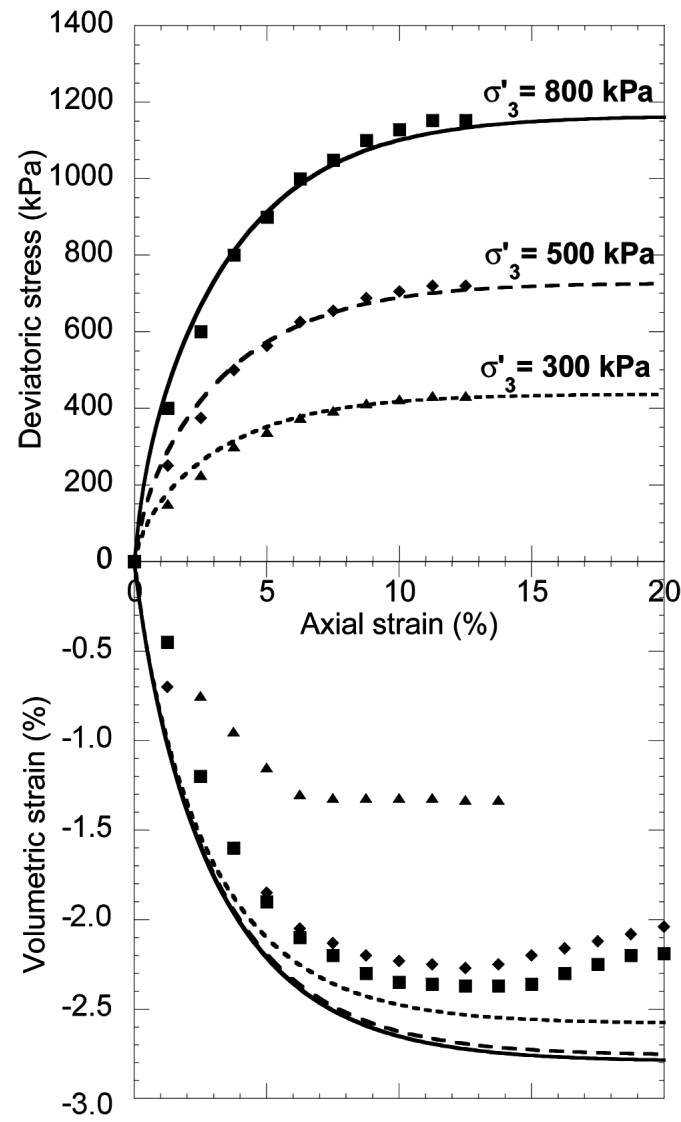

exhibit normally consolidated behaviour with a plateau for the shear strength and volume compression. The hydraulic properties of the materials were introduced in accordance with the hydrogeological characteristics of the slope (see the section titled Numerical simulation).

The different samples were observed to be heterogeneous with elements of limestone, sandstone, dolomite, flysch, and Quaternary deposits in a clayey silt matrix. This heterogeneity occurs mainly at a local scale (at the scale of the sample). However, as far as the mechanical properties of each soil sample are concerned, good homogeneity is exhibited at the scale of the landslide. Moreover, by comparison with other landslides developing in flysch (see, for instance, Tacher et al. 2005), it is well known that such geological formations present good homogeneity of the mechanical properties at the hectometric scale (at least close to the slip surface). The characteristics of each material family (loose soil, slip surface, and bedrock) were, therefore, assumed to be spatially constant (however, the elastic parameters evolve with depth through the nonlinear elasticity).

\section{Period considered for modelling}

Because of data availability and correspondence of the data to a period of significant movement, the year 2000 was chosen to perform all the modelling. During this year, two critical phases with a reactivation of the movements were observed with a good correlation with the snowmelt phase (April) and with a violent thunderstorm that occurred during
Fig. 12. Comparison of the results of the oedometer compression test simulation (continuous lines) and experimental points.
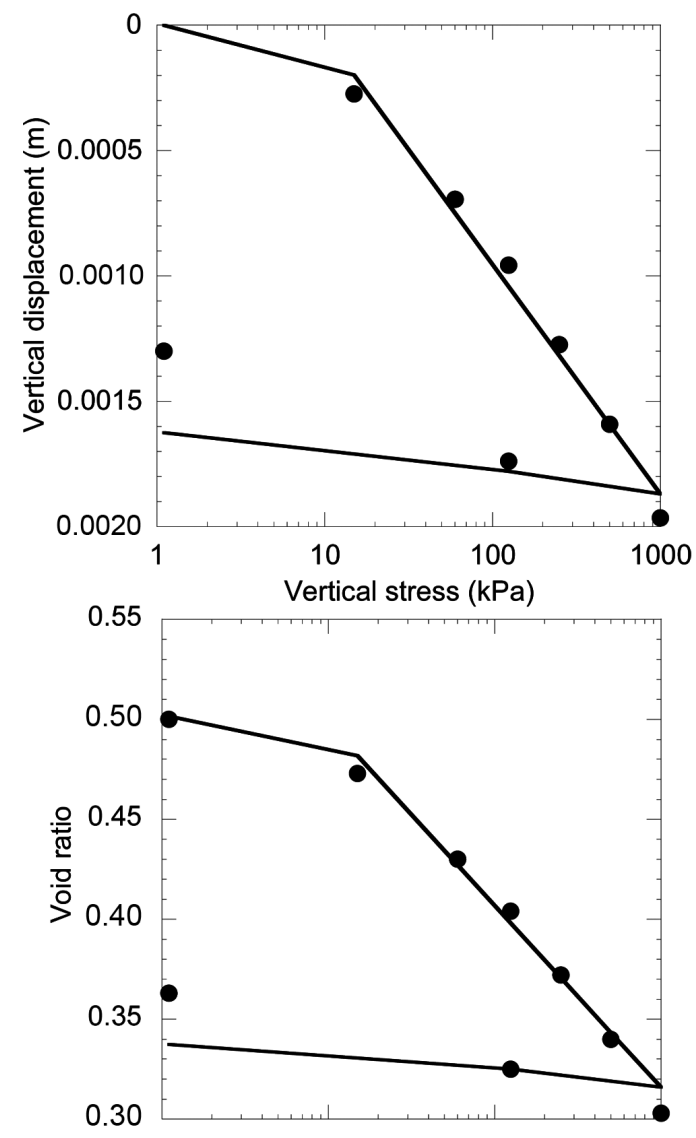

the summer (August) (Fig. 13). The choice of this specific year (i.e., 2000) is also justified by the fact that the return period of the annual rainfall was quite important (42 years).

\section{Numerical simulation}

\section{Hydrogeological modelling}

Groundwater modelling was addressed by the Feflow ${ }^{\circledR}$ finite element software. Computed groundwater pressures were then exported for each day as boundary conditions for the geomechanical model solved in $Z_{-}$Soil ${ }^{\circledR}$. As the slide is very thin, the unsaturated zone is of significant importance within the sliding mass, and thus the flows in the domain are governed by Richard's equation (Hillel 1980).

\section{Parameters}

Spatially, the finite element mesh extension encompasses the entire landslide area (slide plus old, deep-seated slide zone). The 51772 triangular prismatic elements were distributed over four layers of equal thickness. The bottom of the model was the slip surface. Parameters were assigned to both top layers with respect to data obtained by geophysical investigations (Bernasconi 2003), and homogeneous values were considered for both bottom layers (field permeability $k=2 \times 10^{-4} \mathrm{~m} / \mathrm{s}$ ) (Fig. 14). In both cases, the high values to the east correspond to the old, deep-seated slide zone $\left(k=5 \times 10^{-3} \mathrm{~m} / \mathrm{s}\right)$. 
Table 4. Material properties considered in the finite element simulations.

\begin{tabular}{|c|c|c|c|c|c|c|c|c|c|c|c|}
\hline \multirow[b]{2}{*}{ Soil type } & \multirow[b]{2}{*}{ Constitutive law } & \multicolumn{6}{|c|}{ Mechanical properties } & \multicolumn{4}{|c|}{ Hydraulic properties } \\
\hline & & $v$ & $e_{0}$ & $\kappa$ & $\lambda$ & OCR & $M$ & $K(\mathrm{~m} / \mathrm{s})$ & $S_{\text {r,res }}$ & $\alpha\left(\mathrm{m}^{-1}\right)$ & $\beta_{\mathrm{f}}\left(\mathrm{Pa}^{-1}\right)$ \\
\hline Loose material & Elastic law & 0.25 & 0.5 & 0.03 & - & - & - & $10^{-4}$ & 0.1 & 2 & $4.5 \times 10^{-10}$ \\
\hline Slip surface & Modified Cam-Clay model & 0.25 & 0.5 & 0.01 & 0 & 1 & 1 & $10^{-4}$ & 0.1 & 2 & $4.5 \times 10^{-10}$ \\
\hline
\end{tabular}

Fig. 13. Water infiltration in the slope above $1150 \mathrm{~m}$ asl (thin line, right scale) in parallel with the observed displacements in inclinometer B5 (thick line, left scale). The location of inclinometer B5 is shown in Fig. 8. Dates are given as day-monthyear.

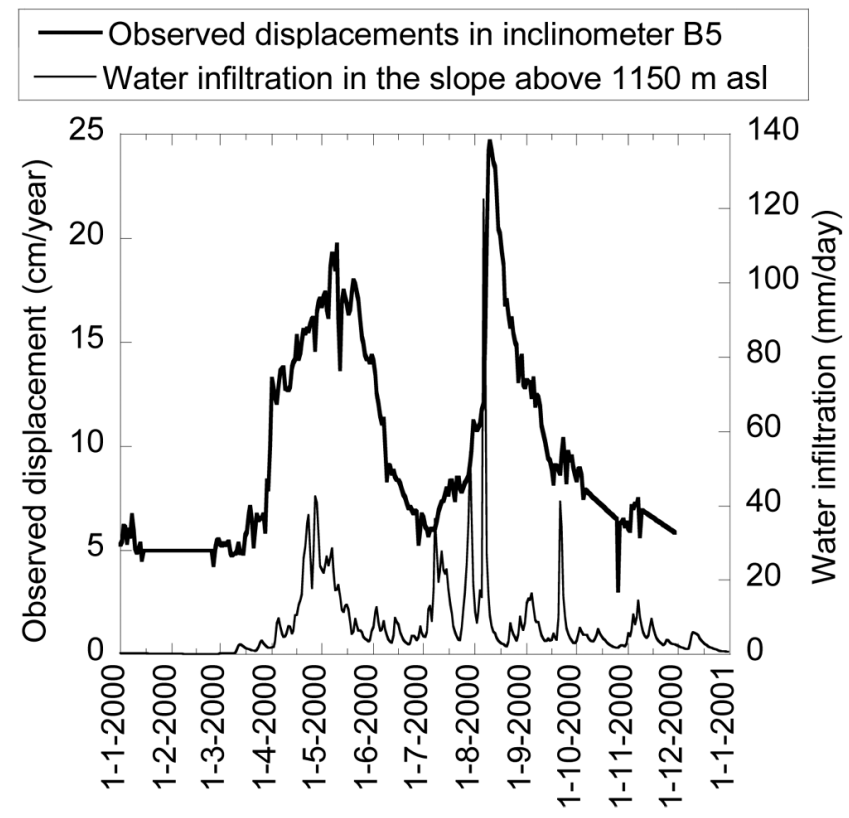

In the sliding mass, porosities $n$ were linearly traced on permeabilities, leading to values ranging from 0.15 to 0.25 . In the old, deep-seated slide and in the two bottom layers of the sliding mass, $n=0.15$.

The old, deep-seated slide zone has little importance in the hydrogeological model because it is almost completely unsaturated. It was discretized, however, to allow for the introduction of flux boundary conditions at the bottom of the mesh along the Arosa zone (Fig. 9). Moreover, assigning homogeneous properties for both bottom layers, rather than continuing the surface heterogeneities down to the slip surface, can be justified by the following arguments: $(i)$ it avoids giving too much weight to structures that are probably very superficial; (ii) such a smoothing does not affect the path of direct infiltration through the surface; and (iii) over depth, the heterogeneity of $k$ has a significant impact only if high-permeability heterogeneities are connected, otherwise they behave as isolated pockets, which is the assumption made for this case.

Unsaturated parameters linking permeability to saturation and suction to saturation are not documented for the site. They were assigned in a homogeneous way to represent coarse materials, i.e., a steep transition between saturated and unsaturated zones (linear model with fringe pressure $=-4.1 \mathrm{~m}$ and residual saturation $=0.1$ ).

\section{Boundary conditions}

Direct infiltration at the surface of the model was computed using the COUP model (Jansson and Karlberg 2001) for five elevation classes, i.e., the zones included between the following isolines: $625,875,1125,1375$, and $1625 \mathrm{~m}$ above sea level (asl). Hydraulic head conditions ( $h=$ elevation $z$ in metres) with constraint of outgoing rate were also imposed at the locations of observed springs. At the toe of the slope, the condition $h=z-2(\mathrm{~m})$ was imposed at the contact with Rhine valley alluvia (Fig. 9).

The inflow from the Arosa zone was imposed at the bottom interface as a rate condition. To represent both conductive and capacitive effects of the sandstones, infiltration from the Valüna valley was reduced and a base level was assumed as follows (Fig. 15):

$$
Q_{\text {Arosa }}=\mathrm{IE}_{\text {Arosa }} \times S_{\text {Arosa }} \times p
$$

where $Q_{\text {Arosa }}$ is the rate of inflow feeding the landslide through the sandstones above the Arosa zone (in $\mathrm{m}^{3} /$ day), $\mathrm{IE}_{\mathrm{Arosa}}$ is the infiltration computed by the COUP model in the Valüna valley $\left(\mathrm{m}^{3} /\left(\right.\right.$ day $\left.\left.\cdot \mathrm{m}^{2}\right)\right), S_{\text {Arosa }}$ is the area of the Valüna basin (approx. $12 \mathrm{~km}^{2}$ ), and $p$ is the percentage of water of the Valüna basin directed towards the landslide through the limestones (approx. 25\%). Then, if $Q_{\text {Arosa }}<$ $27000 \mathrm{~m}^{3} /$ day, $Q_{\text {Arosa }}=27000 \mathrm{~m}^{3} /$ day, which represents the base flow; and if $Q_{\text {Arosa }}>27000 \mathrm{~m}^{3} /$ day, $Q_{\text {Arosa }}=\left(Q_{\text {Arosa }}-\right.$ $27000)^{1 / 2} \times 10$, which is a calibration that represents the absorption of infiltration events.

Except for the rate conditions along the Arosa zone and head conditions at the toe, no boundary conditions were set up at the bottom interface, which means that the hydraulic relations of the landslide with the underlying flysches were neglected. Indeed, these flysches are assumed to have a relatively low permeability.

\section{Results}

The transient hydraulic balance shows that the direct infiltration in the year 2000 reached $7.52 \times 10^{6} \mathrm{~m}^{3}$ and the inflow through the Arosa zone was about $9.86 \times 10^{6} \mathrm{~m}^{3}$ (Fig. 16). The outflow curve was smoother than the inflow events because of the capacitive function of the landslide. Typically, the 6 August storm response was absorbed and delayed. The cumulated rate of the springs reached $1.06 \times$ $10^{6} \mathrm{~m}^{3}$, which represents only a few percent of the total outflow. In May, the snowmelt episode did not lead to spectacular changes in the hydraulic balance because the topography of the slope resulted in progressive the melting from the bottom to the top. For example, when the snowmelt occurred in the Valüna valley, it had already finished on the landslide several days or weeks earlier.

The piezometric behaviour of the slope is illustrated by piezometers B4 and B8 (Fig. 17; location as in Fig. 8). The 
Fig. 14. Isotropic permeability field $k$ in the two top layers $(a)$ and the two bottom layers $(b)$ of the finite element model. (Reproduced with permission of swisstopo (BA071481).)

(a)

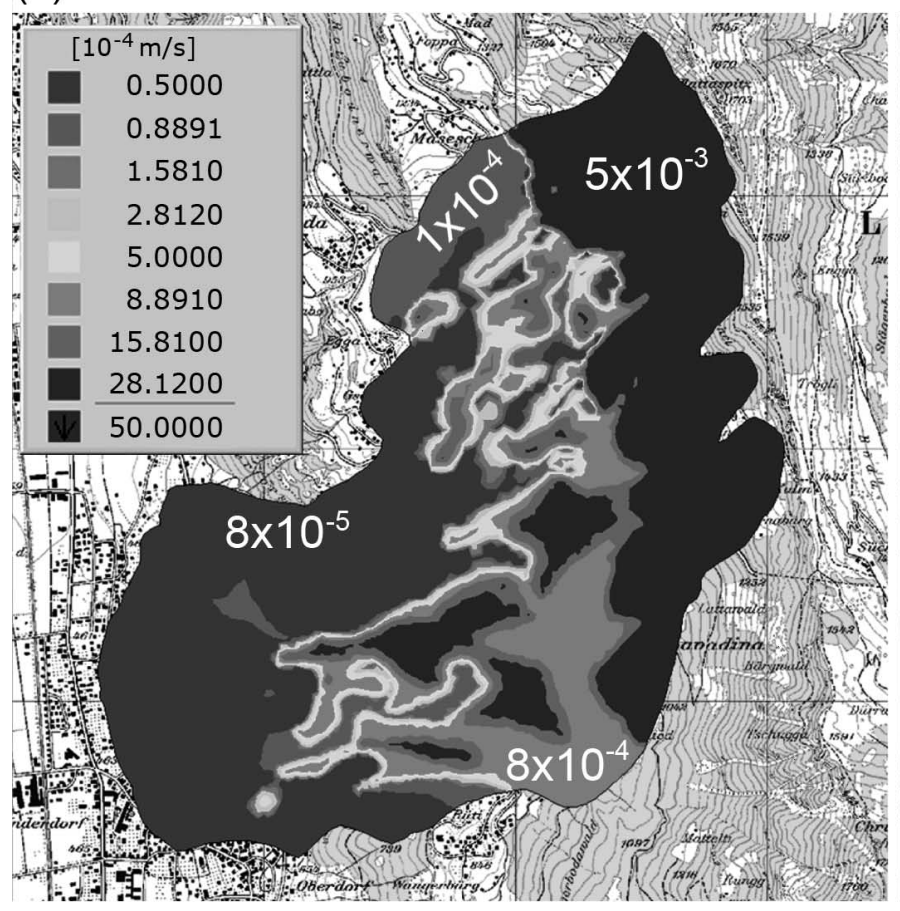

Fig. 15. Inflow from the Arosa zone. Comparison between the total infiltration in the Valüna basin and the inflow in the landslide through the sandstones. Dates are given as day-month-year.

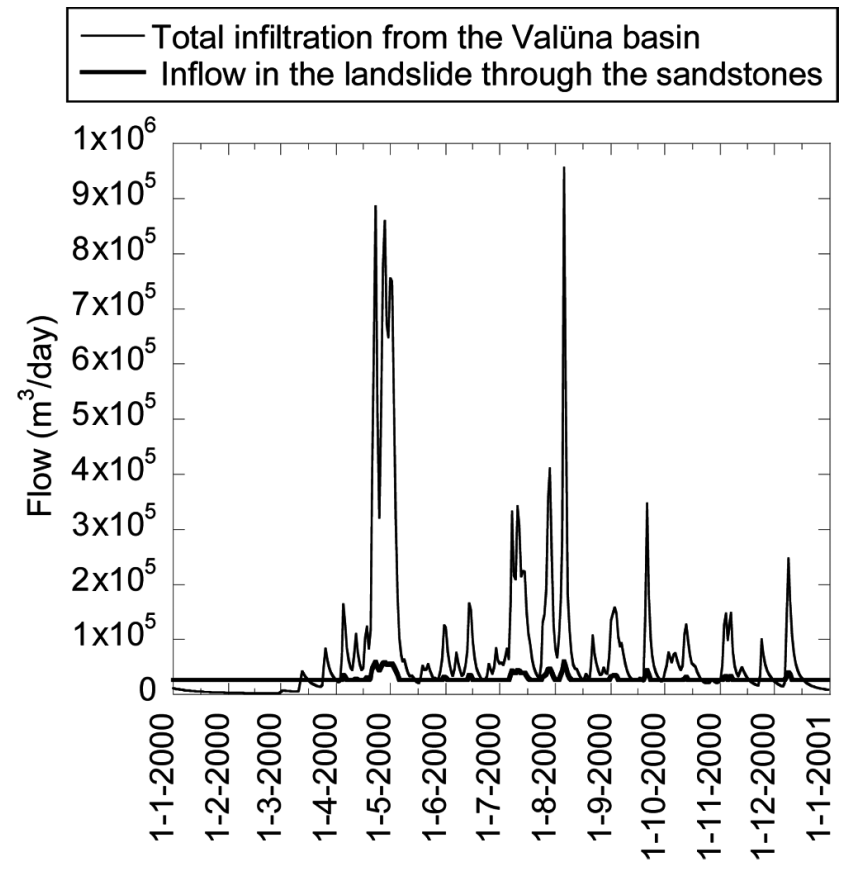

calibration was carried out by comparing the water table data with the hydraulic head computed at the bottom node at these sites, i.e., on the slip surface. The model also agrees with the total spring flow rates, although the detailed behaviour of each piezometer is very sensitive to elevation. Both main events in 2000 were the snowmelt and (b)

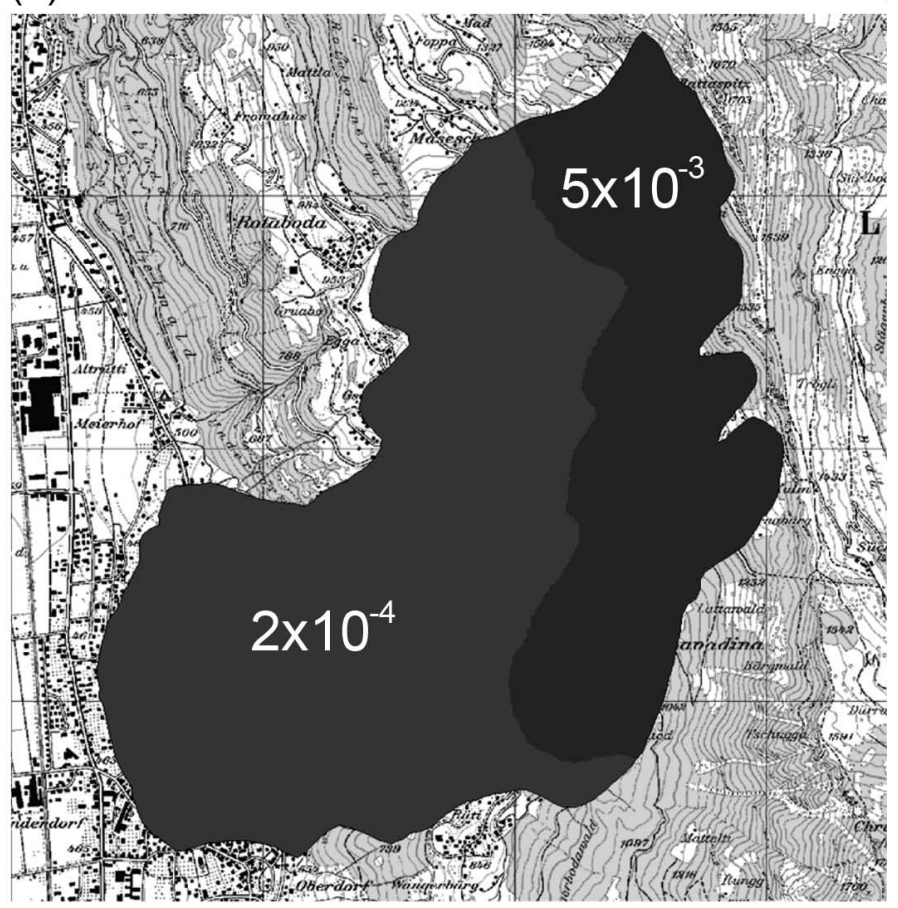

the rainfall at the beginning of August, which led to a peak more than $2 \mathrm{~m}$ high. Just after these peaks, the decrease in head was slower in the model than in reality. This can be explained by the relative smoothing of the parameter field, mainly over depth.

Heterogeneities are also responsible for another observation: during the snowmelt event, the model reacted with a delay of some days with respect to the monitoring data. Local pervious heterogeneities that were not considered in the model accelerated the piezometer response to inflows in the Valüna valley. Such a delay did not occur at the beginning of August because there are inflows to both the Triesenberg and Valüna basins. The feeding role of the Valüna valley through the sandstones covering the Arosa zone was confirmed by the model, since any calibration that did not consider it led to a hydraulic head deficit during winter. Furthermore, both computed and observed hydraulic heads in piezometers located just below the Arosa zone showed a flat behaviour between main inflow events, illustrating the capacitive role of the sandstones (piezometer B4, Fig. 17).

At the slope scale, saturation profiles (Fig. 18) show seasonal conditions. In the old, deep-seated slide zone, inflow from the Valüna valley was not sufficient to saturate the medium, either in dry (winter) or wet conditions (summer), in accordance with the observations. At the toe of the slope, saturation up to the subsurface was permanent, so seasonal fluctuations occurred mainly in the middle of the slope.

The numerical results suggest that the model globally fits reality, despite a simplification of the parameter fields, a rough estimation of the unsaturated parameters, and minimal knowledge of the real hydraulic balance. Computed hydraulic pressures are thus suitable as input to the hydro- 
Fig. 16. Hydraulic balance in 2000. Comparison between the outflow, inflow through the Arosa zone, and direct infiltration on the slope. Dates are given as day-month-year.

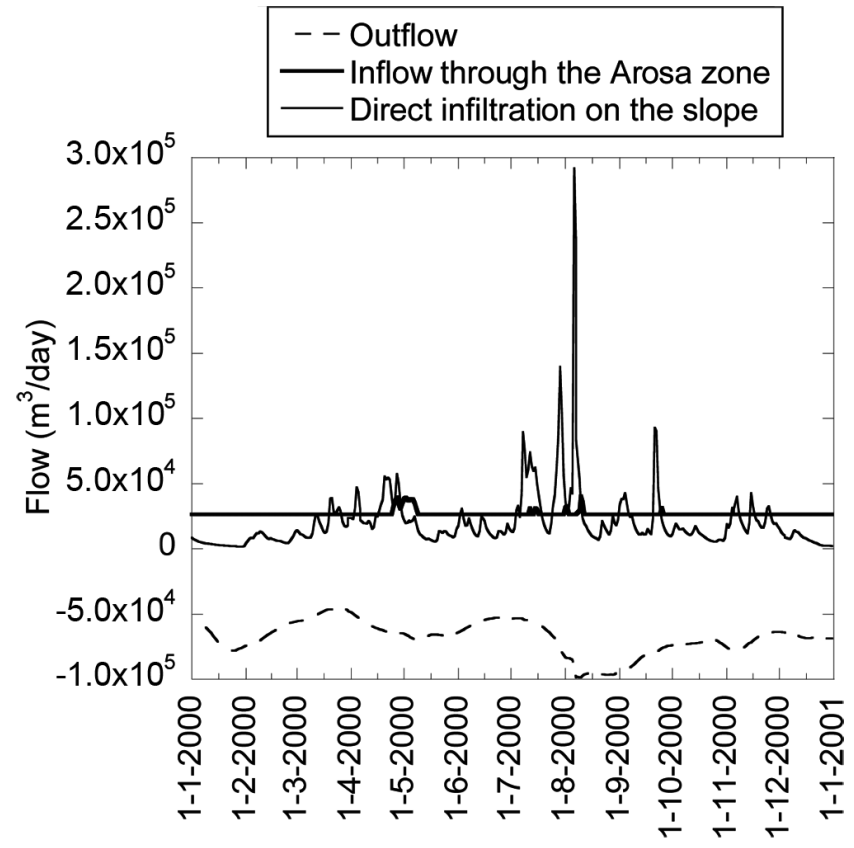

mechanical models to describe the direct causes of the movements during crises.

\section{Geomechanical modelling}

The hydromechanical calculations were performed both in two dimensions (along a cross section defined in the middle of the landslide) and in three dimensions (to obtain a global distribution of the movements) using the program Z_Soil ${ }^{\circledR}$. The unstable zone (i.e., the moving, unstable loose soil and the slip surface) and the first $5 \mathrm{~m}$ of the bedrock below were meshed. Under the bedrock, solid boundary conditions for which the displacements were constrained in the three directions were imposed at each node. Indeed, as justified in the section titled Main features of the landslide, this bedrock was assumed to be stable, even though it is formed of ancient rockfall material.

As mentioned previously, the hydrogeological modelling of the crisis experienced in the year 2000 was performed in a first stage. The calculated pore-water pressure fields resulting from the hydrogeological events of 2000 were then used as input for the geomechanical model.

This approach with two successive and separate simulations (a hydrogeological phase followed by a hydromechanical simulation) enabled consideration of the effect of hydraulic data variation on the mechanical behaviour of the slope. However, the mechanical modifications caused by slope movements were not taken into account in the hydrogeological modelling. This is justified by the relatively low intensity of the movements, which have probably almost no effect on the hydraulic properties of the slope.

\section{Preliminary considerations}

In the $2 \mathrm{D}$ and $3 \mathrm{D}$ meshes, great attention was paid to the size and shape of the elements. To fit with the small-strain approach (eq. [10]), large enough elements had to be used.
Fig. 17. The upper graph shows the direct infiltration in the slope at elevation $1000 \mathrm{~m}$ and infiltration in the Arosa basin, and the lower graph shows a comparison between the computed and measured hydraulic heads in boreholes B4 (left scale) and B8 (right scale). Dates are given as day-month-year.

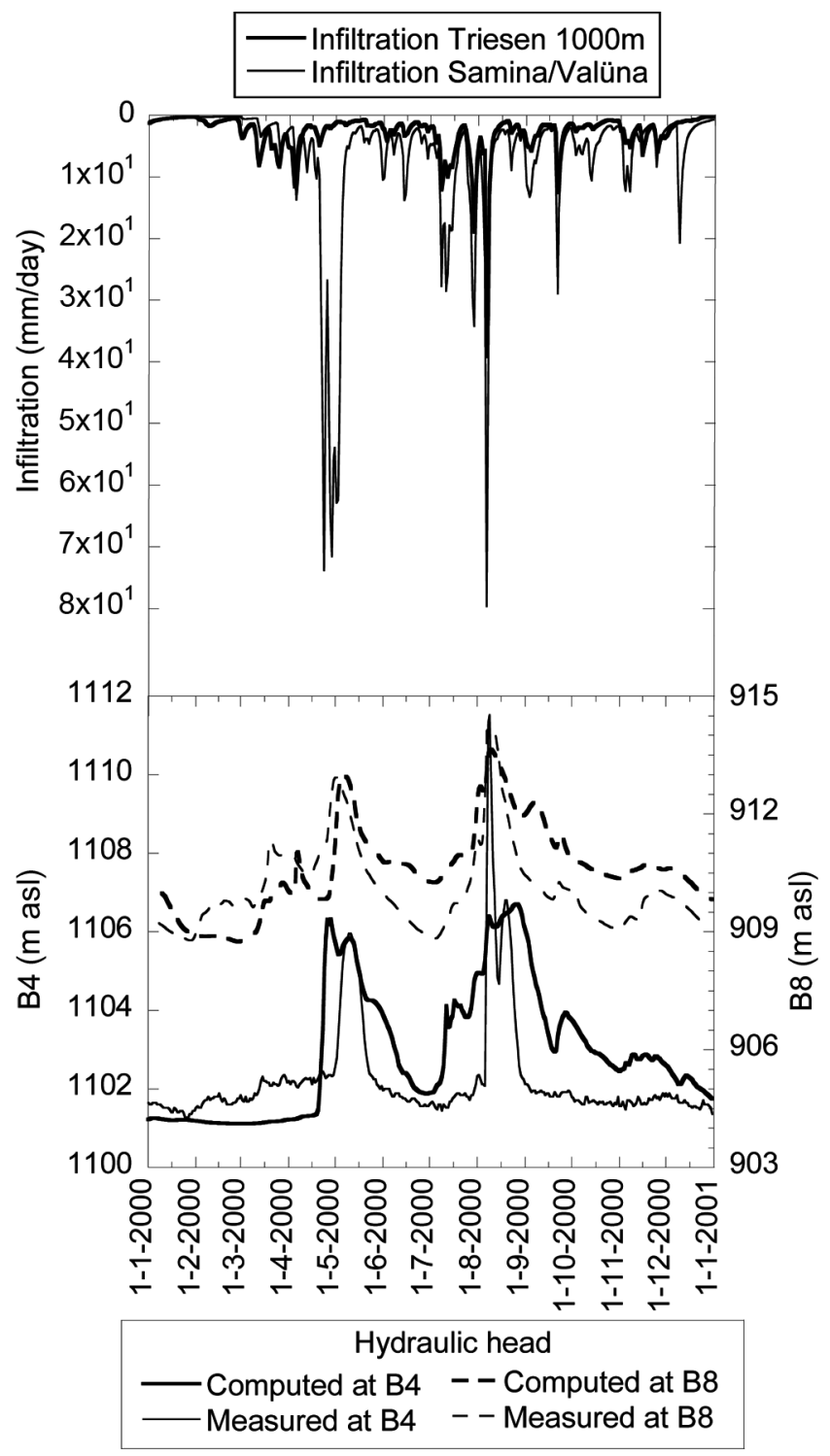

During the 1 year period modelled, the maximum shear displacement of the slip surface elements was about $10 \mathrm{~cm}$. The small-strain approach requires strains lower than $20 \%$. Therefore, the element size has to be greater than $50 \mathrm{~cm}$, which is the case because the lesser dimension of one element corresponds to the height of the slip surface (e.g., $1 \mathrm{~m})$. Another problem with modelling such a long slope with a thin failure surface is related to the aspect ratio of the element. Therefore, elements $16 \mathrm{~m}$ in length were used to represent the $1 \mathrm{~m}$ thick slip surface. The minimum aspect ratio was thus $1: 16$, which remains within acceptable limits.

The effect of the distance between each imposed pressure node was considered. Figure 19 shows that, due to the low permeability of the materials, too great a distance between each point for an imposed pressure introduces an irregularity in the pressure field. Lastly, a decision was made to impose 
Fig. 18. Vertical saturation sections in the model in 2000. The upper profile is for 11 June, and the lower profile for 23 April.

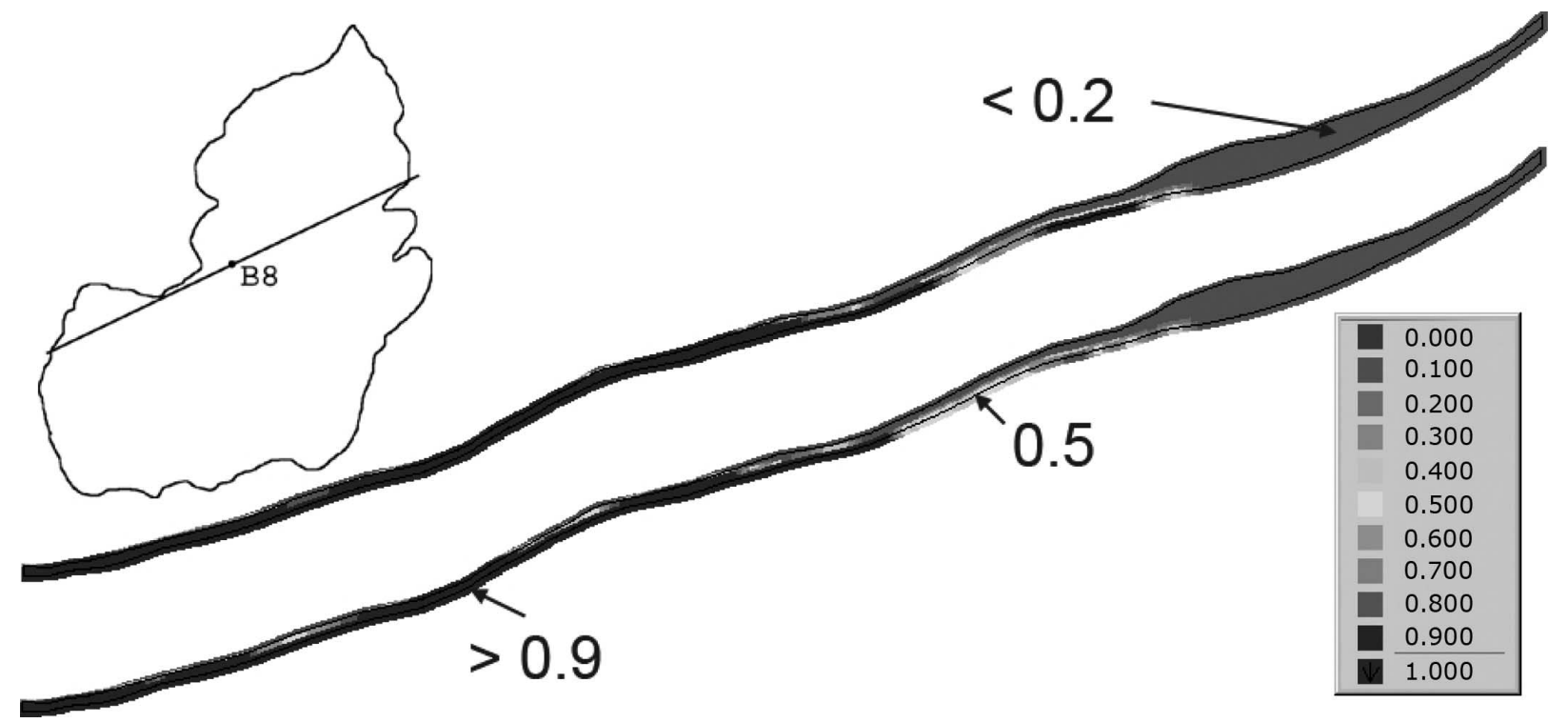

Fig. 19. Effect of a large distance between each imposed pressure in the hydromechanical model.

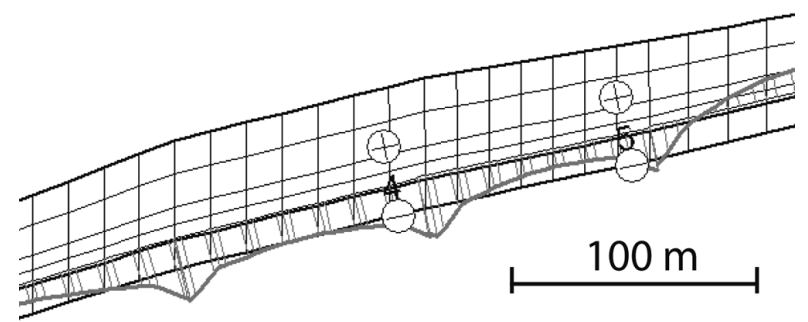

the pressure value at each node for the $2 \mathrm{D}$ model and on the three first rows of nodes for the 3D model. This corresponds to a distance of some $16 \mathrm{~m}$ between each imposed pressure. This means that the pore-water pressure at each time step for the $2 \mathrm{D}$ calculations is an input datum at each node, whereas the pore-water pressure for the 3D calculations is calculated on the two upper rows of nodes using eq. [6].

The effect of the mechanical boundary conditions at the toe of the landslide was studied in two dimensions. Four alternatives were foreseen: equivalent linear forces with active $\left(K_{\mathrm{a}}=1 / 3\right)$, passive $\left(K_{\mathrm{p}}=3\right)$, and at-rest $\left(K_{0}=1\right)$ coefficients and fixed solid boundary conditions. The results show that these toe boundary conditions have a very local and almost negligible influence on the obtained results (Fig. 20). Therefore, to introduce simpler data, fixed boundary conditions were used.

The influence of the old, deep-seated slide zone on the general distribution of the movements was modelled in two dimensions. The materials forming this zone are mainly rock blocks connected by a locally weathered rock mass and may be considered as a nondeformable material (represented here by an elastic law with very high rigidities). No information exists about the mechanical properties of this zone. The following elastic Young's modulus values were used one after the other for this zone: $75 \mathrm{MPa}$ (similar to that of the loose soil), $120 \mathrm{MPa}$, and $200 \mathrm{MPa}$. Figure 21 shows the corre-
Fig. 20. Study of the effect of the mechanical boundary conditions, at the bottom of the landslide, on the movement of the slope.
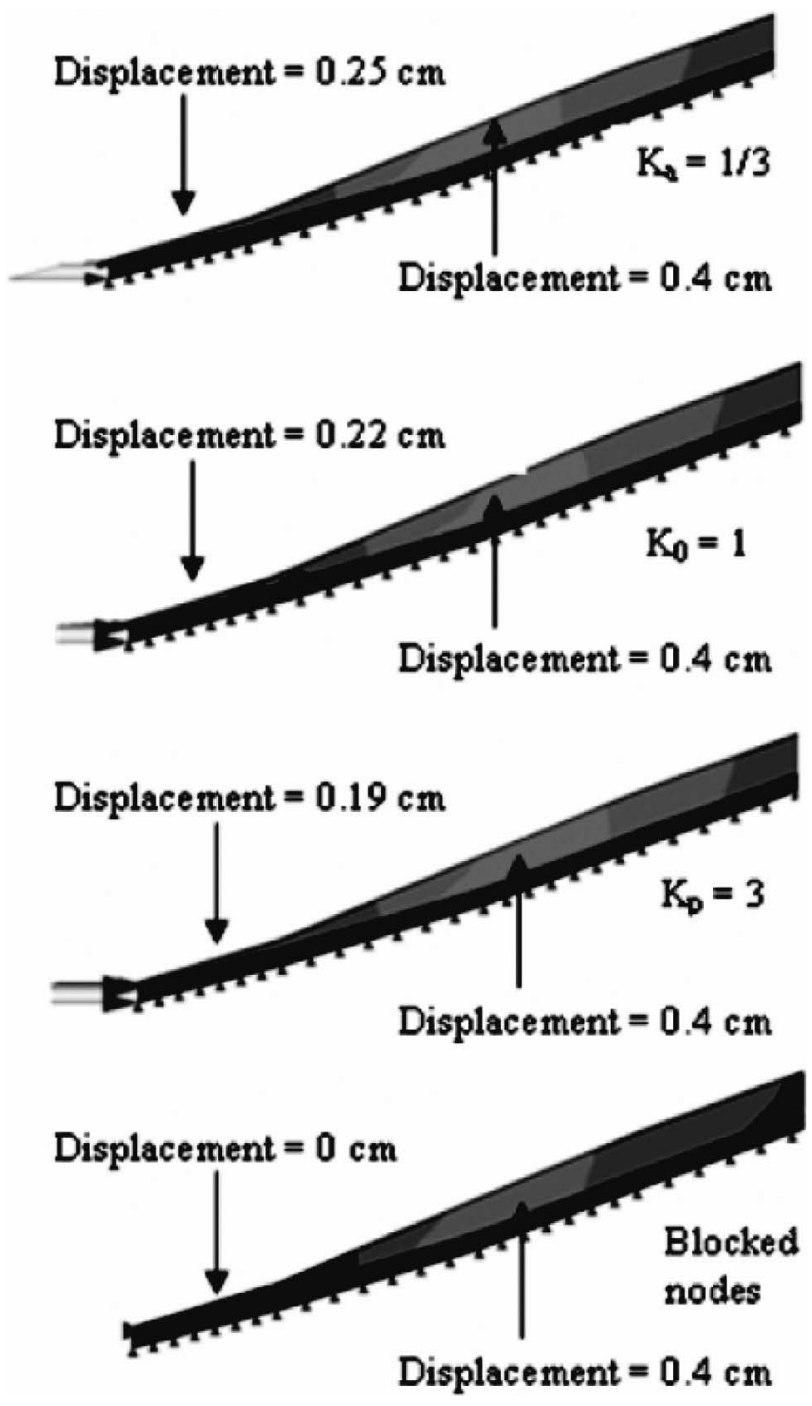
Fig. 21. Study of the effect of the deep-seated slope movement zone on the movement of the slope. E, the Young's modulus.
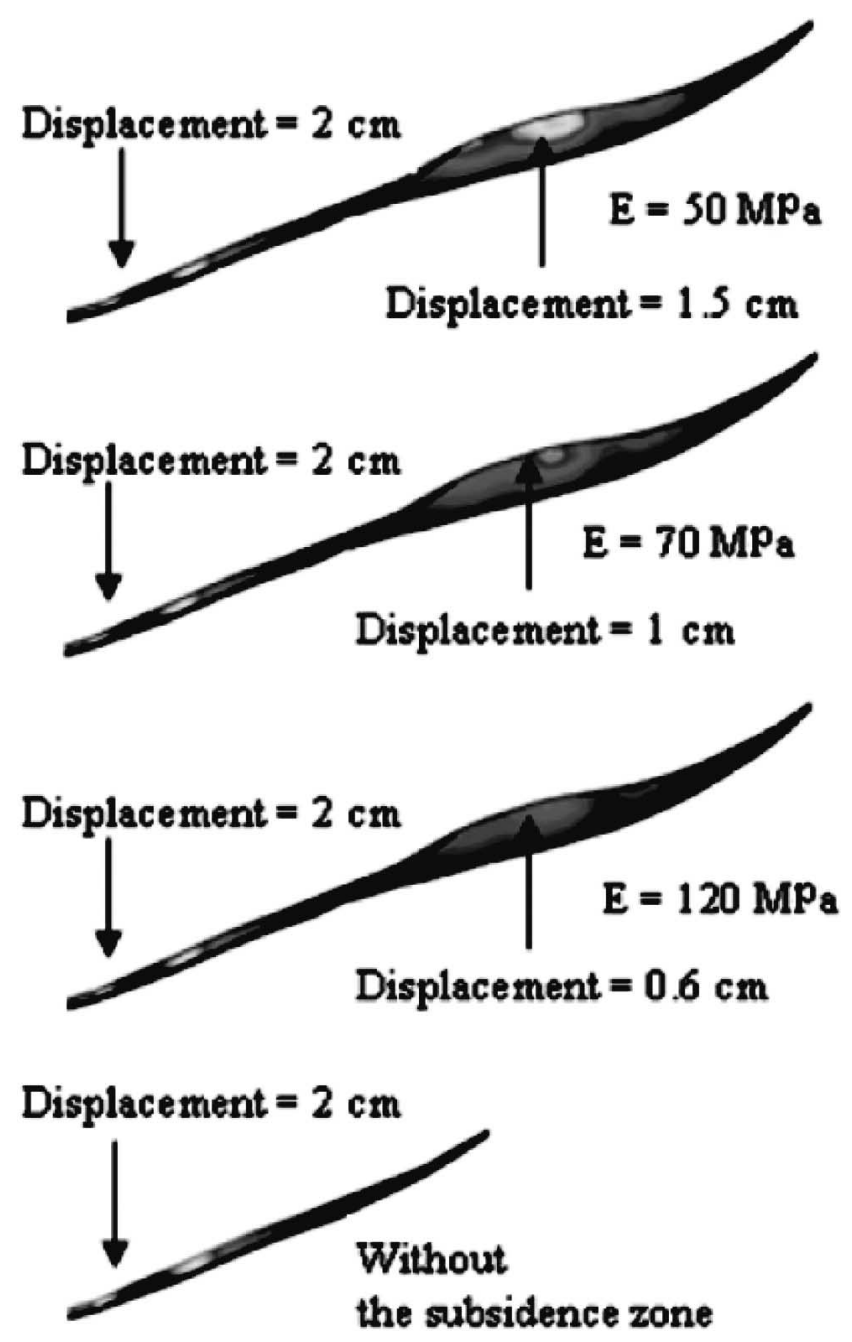

sponding results, and it can be observed that this old, deepseated slide zone had no influence on the movement of the current lower instability.

\section{Two-dimensional modelling}

The selected cross section for the $2 \mathrm{D}$ model should be quite representative of the global 3D behaviour of the landslide. The direction of this cross section is shown in Fig. 8, and the profile is presented in Fig. 2. The choice of this cross section was influenced by several factors: $(i)$ this profile crosses the village of Triesenberg, in which the largest velocities of displacement have been observed, and these movements have caused significant damage to the infrastructures linked to the village; (ii) the information concerning movement (inclinometers) and the material characteristics is mainly concentrated along the axis of this cross section or near it; (iii) several preliminary studies (related to hydrogeological, geological, and topographical data) have been carried out along this cross section; and (iv) the lateral 3D boundary effects can be neglected because this profile spans the middle of the slope.
Fig. 22. Representation of the $2 \mathrm{D}$ mesh of the hydromechanical model. $L$, the total length of the 2D mesh; $\Delta h$, the total difference in elevation of the $2 \mathrm{D}$ mesh.

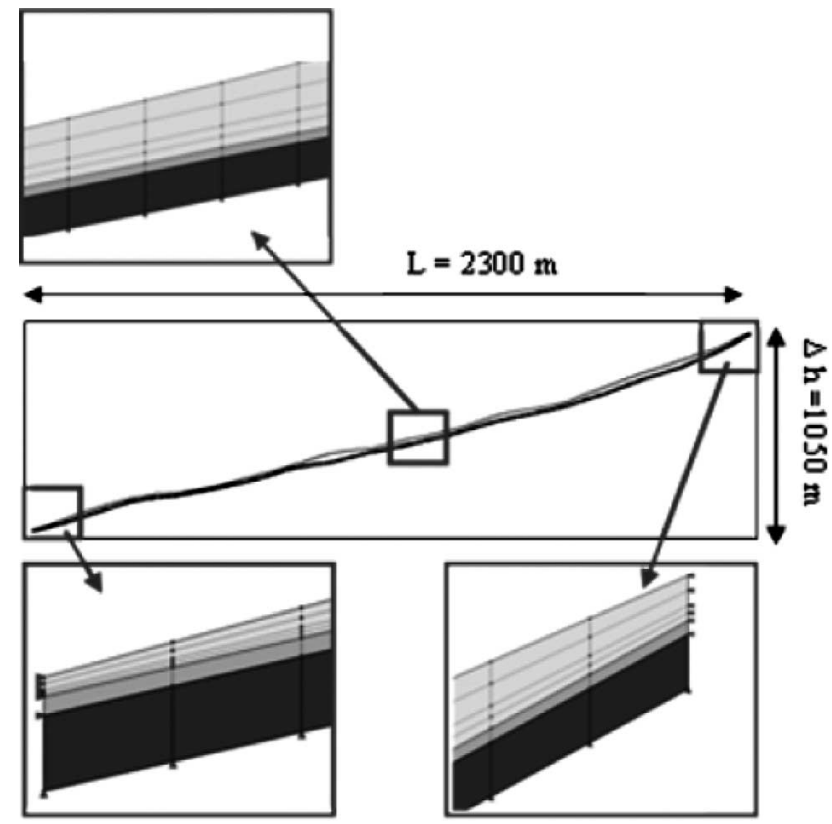

Table 5. Characteristics of the $2 \mathrm{D}$ mesh.

\begin{tabular}{ll}
\hline Nodes & 2359 \\
Elements & 2016 \\
Solid boundary conditions & 345 \\
Water boundary conditions & 2359 \\
Load-time functions & 2359 \\
Different materials & 3 \\
\hline
\end{tabular}

The mesh, composed of four-noded elements for solid displacements and pore-water pressure, is shown in Fig. 22, and its characteristics are given in Table 5. The modelling was performed for a period of 291 days (from 1 January to 18 October 2000) using time steps equal to 1 day. The hydraulic conditions resulting from the hydrogeological modelling were defined day by day through load-time functions.

\section{Interpretation of the two-dimensional results}

Qualitatively, the results obtained reveal two main active zones, one on the top of the slope and the other approximately in the middle of the slide profile (Fig. 23). The upper active zone is clearly seen on the map of the average annual displacements (Fig. 4), but no significant comparison can be made because of the difference in the period considered (i.e., the year 2000 versus the period 1976-1997). A quantitative assessment of the modelled movement can be made using the data from two inclinometers. Indeed, these boreholes are close to the active zone in question (Fig. 8), and the available data span the considered period (year 2000). By comparison with the general trend of inclinometer KL1A, the order of magnitude of the modelled displacements is very similar and the calibration of the model is quite satisfactory, although the crisis periods are not monitored in detail (Fig. 24). The continuous displacements observed in inclinometer B5 are higher than those obtained with the simula- 
Fig. 23. Distribution of the displacements after the 291 days of simulation (1 January to 18 October 2000).

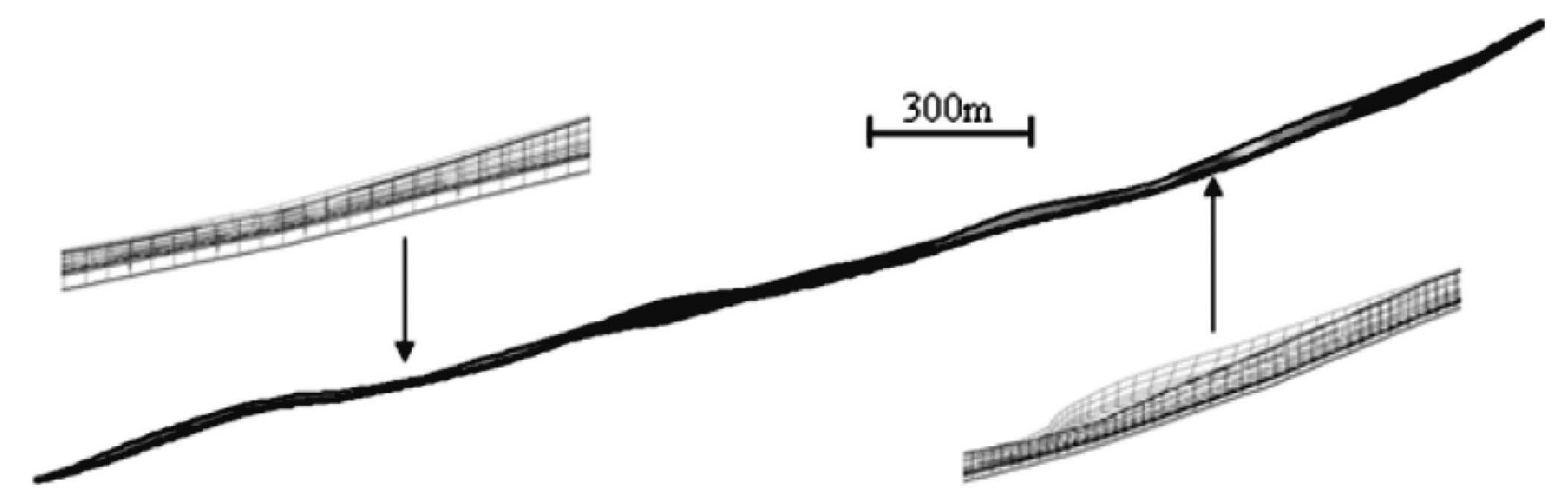

Fig. 24. Calibration of the model: comparison of the results with data from two inclinometers. The trend of the KL1A measurement is interpolated. The numerical modelling refers to a point at the surface close to the location of inclinometer KL1A. Dates are given as day-month-year.

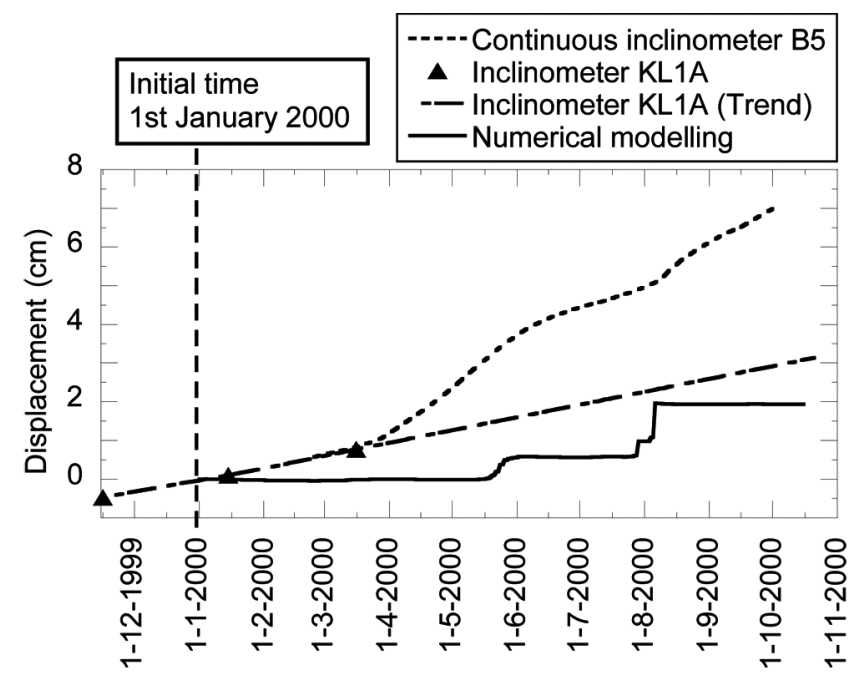

tion, but this can be due to the distance separating the cross section from the inclinometer (about $300 \mathrm{~m}$ ). Nevertheless, the trend of the simulated displacement with respect to time is very discontinuous, whereas it is more continuous in reality. This imprecision is caused by the constitutive model (modified Cam-Clay model). Such a model considers that only monotonic loadings are able to induce plasticity. Therefore, the cyclic behaviour of the material is not completely reproduced, as the progressive plasticity occurring during mechanical unloading (due to the water pressure field variation) is not taken into account with this constitutive law. Therefore, the model results are necessarily slightly lower than the real movements.

To improve the interpretation of the model results, parametric studies were carried out to evaluate the effect of the selected friction angle of the material forming the slip surface and the influence of the water pressure variation. Simulations with six different friction angles $\left(30^{\circ}, 28^{\circ}, 25^{\circ}, 23^{\circ}\right.$, $22^{\circ}$, and $21^{\circ}$ corresponding to $M=1.20,1.10,1.00,0.90$, 0.86 , and 0.81 , respectively) and three water pressure values $(\times 1.00, \times 1.25, \times 1.50$, which are the normal case and then a general increase of all pressure field variations by $25 \%$ and
$50 \%$, respectively) were considered. The results are shown in Fig. 25. One can observe that the effect of the increase in the variation of the water table level is almost linear and relatively minor for the three higher friction angles that are most likely, and the influence of the friction angle is more nonlinear. The multiplication of the pressure field values by 1.50 can be seen as an extremely unfavourable case that would never occur, even in severe climate-change conditions, as proven by appropriate hydrogeological simulations.

\section{Three-dimensional modelling}

Based on the preliminary morphological analyses and given the distribution of the monitored movements in the slope, the initial slide that was considered as a single phenomenon may be subdivided into three quasi-independent landslides (see the section titled Main features of the landslide). This assumption enables the carrying out of three independent simulations using three distinct meshes. This decreases the size and time of each calculation considerably. On the other hand, it allows a more extensive mesh for an identical calculation time. The boundaries separating each modelled landslide were represented by solid boundary conditions constraining the displacements perpendicular to the boundary and enabling movement in the direction of the slope.

Due to the reduced thickness of the slip surface $(1 \mathrm{~m})$, the longitudinal dimensions of the elements were limited to $16 \mathrm{~m}$ to respect the acceptable distortion of one finite element. This requires a relatively high number of elements for each landslide. The characteristics of the meshes of the three considered slides are given in Table 6. Eight-noded 3D finite elements were used for solid displacements and for porewater pressure.

\section{Interpretation of the three-dimensional results}

Qualitatively, the distribution of the movements obtained by the $3 \mathrm{D}$ simulations is fairly similar to that of the values drawn from the average annual displacement map obtained by surveys and GPS measurements (Fig. 4). Indeed, the model results reveal one main active zone within each slide that is small in size. Theses zones are located in the middle of the slope for slides 1 and 2 and at the top part of slide 3 . These results are graphically presented in Fig. 26. Moreover, the quantitative evolution of the displacements in each active zone, shown in parallel with the evolution of the pore-water pressure at the slip surface level, is given in Fig. 27. The order of magnitude of the model results is slightly lower than 
Fig. 25. Parametric study of the effect of the possible variation of $(a)$ the multiplication of water pressure values and $(b)$ the friction angle on the magnitude of displacements obtained in the upper active zone. $\Phi$, friction angle; $\Delta p$, change in water pressure.

(a)

(b)

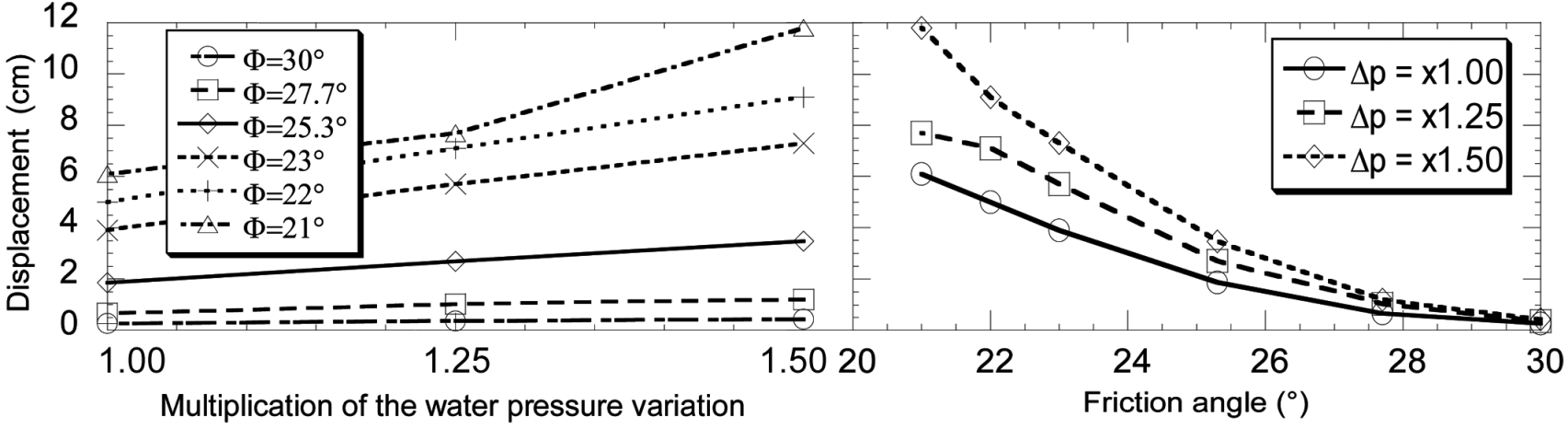

Table 6. Characteristics of the three 3D meshes.

\begin{tabular}{llll}
\hline & Landslide & Landslide & Landslide \\
& 1 & 2 & 3 \\
\hline Nodes & 22928 & 34695 & 17803 \\
Elements & 17760 & 27117 & 13728 \\
Solid boundary conditions & 5760 & 8405 & 4638 \\
Water boundary conditions & 13557 & 13622 & 10497 \\
Load-time functions & 13557 & 13622 & 10497 \\
Different materials & 3 & 3 & 3 \\
\hline
\end{tabular}

the average annual displacements given in Fig. 4. However, they fit quite well with the displacements that had been obtained by InSAR monitoring between August 1992 and August 2001 (Colesanti and Wasowski 2004). These results, which were fortuitously discovered and interpreted by one of the authors after the modelling phase of the project, tend to confirm the importance and spatial distribution of the modelled displacements. During this monitoring programme, it was observed that velocities in the line-of-sight direction (LOS velocities) did not exceed $\pm 20 \mathrm{~mm} /$ year. If it is assumed that $(i)$ the slope faces west, $(i i)$ the motion is purely translational (downslope), and (iii) the local inclination of the slope is approximately $24^{\circ}$, the LOS velocity has to be scaled with the factor 1.45 to obtain the real velocity. This yields a maximum slope displacement of approximately $30 \mathrm{~mm} /$ year, which is very close to the model results.

Unfortunately, in terms of inclinometer data, no other information than that presented in Fig. 24 is available for the period considered in the modelling, making a more precise quantitative comparison impossible.

The irreversible evolution of displacements in the graphs in Figs. $27 b$ and $27 c$ clearly exhibits an elastoplastic behaviour of the slip surface in the corresponding zones, whereas the quasi-parallel evolution of water pressures and displacements in the graph in Fig. $27 a$ shows a purely elastic and reversible behaviour of the soil in the upper part of the slope. The displacements are largely influenced by both crises due to the snowmelt of April and the thunderstorm event of August 2000. Indeed, the total displacements obtained after the 291 days of simulation (from 1 January to 18 October 2000) are essentially created during both short crisis periods.

With respect to the $2 \mathrm{D}$ modelling, the $3 \mathrm{D}$ simulations display worthwhile additional information on the general mechanical
Fig. 26. Distribution of the obtained displacements after 291 days of simulation (from 1 January to 18 October 2000) and location of the three more active zones. The pore-water pressure and the displacement evolutions in these zones are given in Fig. 27.

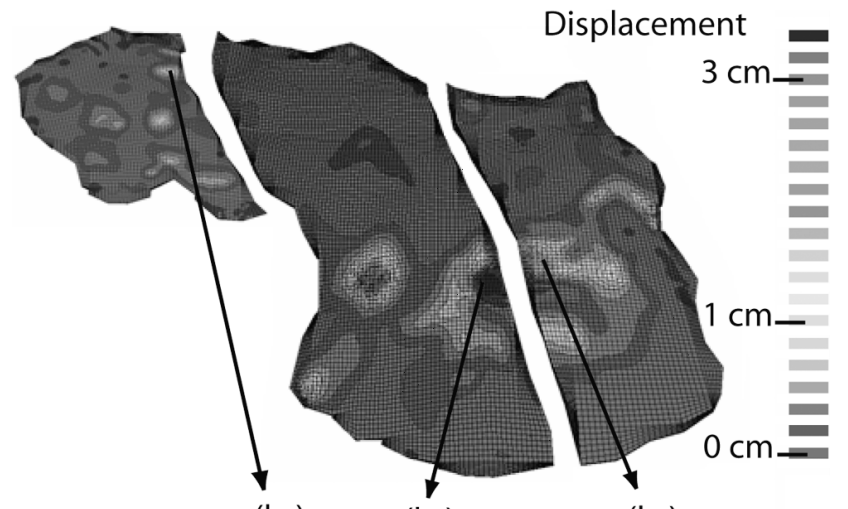

$\left(b_{3}\right)$

$\left(b_{2}\right)$

$\left(b_{1}\right)$

behaviour of the slope. In particular, it is possible to conclude that the zones where the movements are more significant and may increase damage to the infrastructure are very limited in space and have little influence on the surrounding zones. Therefore, in a mitigation attempt, simple local drainage in these three zones would probably be quite efficient.

Similar to analyses carried out in the 2D modelling, calculations were performed considering a hypothetical, extremely unfavourable case by multiplying each value of the pressure field by a factor of 1.50 . This process can be seen as a stability analysis in which the driving forces (linked to water pressure) are increased and the resisting forces (linked to the material parameters) are kept constant. Figure 28 shows the displacements obtained after 291 days of simulations in the normal configuration and in the extreme case for the three locations given in Fig. $26\left(b_{1}, b_{2}\right.$, and $\left.b_{3}\right)$. As expected, the amplification of the water pressure causes an increase in the obtained displacements of the slope. However, this increase remains quite acceptable in terms of risk assessment.

\section{Conclusions}

The analysis of a large landslide by means of finite element modelling is a very efficient method to study aspects 
Fig. 27. Evolution of the obtained displacements at the surface and the corresponding pore-water pressures at the level of the slip surface in the same zone during the crisis of the year 2000 in three active zones reported in Fig. 26: $(a) b_{3} ;(b) b_{2} ;(c) b_{1}$.

(a)

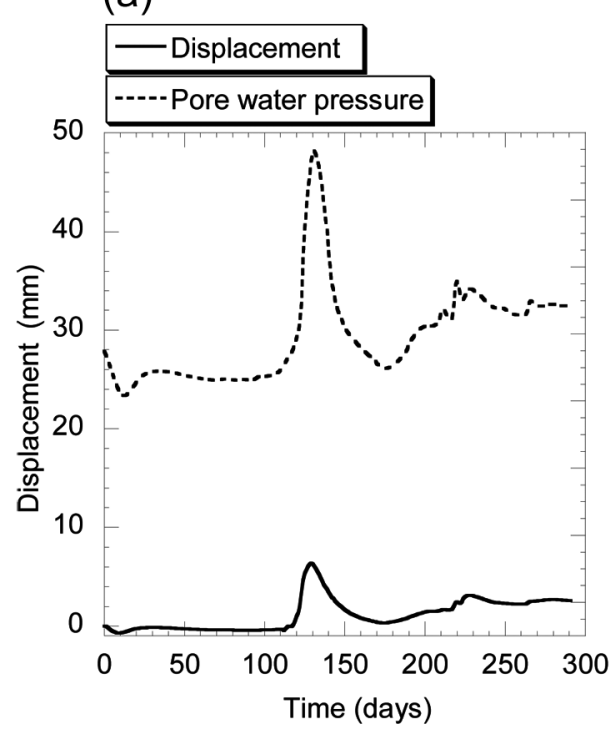

(b)

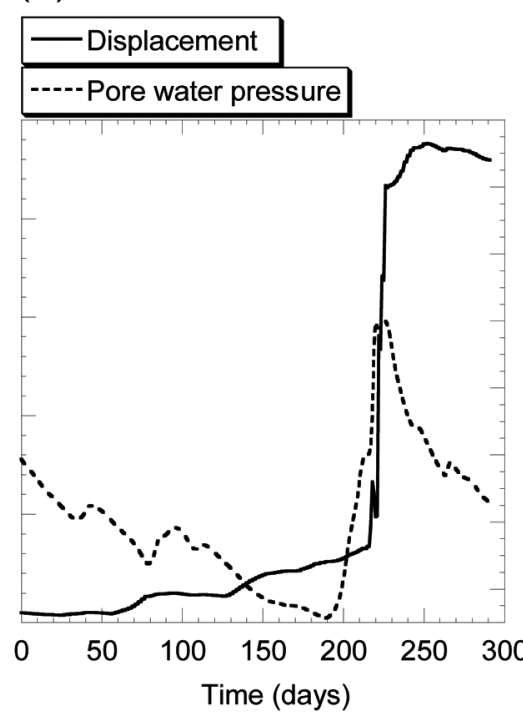

(c)

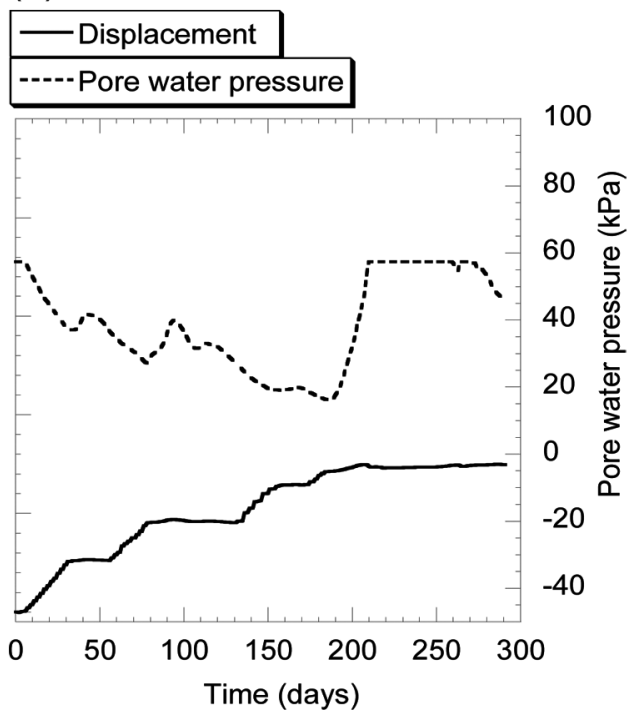

Fig. 28. Comparison of the obtained final displacements at three specific points with the normal pressure field configuration and the extreme pressure field (multiplied by 1.50).

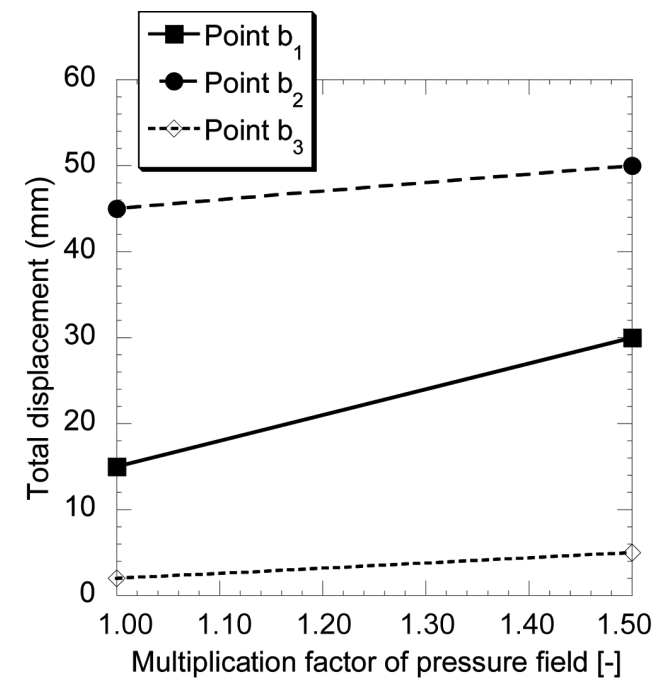

of natural slope movements. In the present case dealing with the Triesenberg landslide, the water pressure variation in the slope is the major cause of the movements. Therefore, consideration of the hydromechanical couplings allows a detailed analysis of acceleration phases. A finite element analysis was carried out to determine the hydromechanical behaviour of the Triesenberg landslide, using a transient pressure field in the slope established by a separate hydrogeological unsaturated model. For the geomechanical modelling, the use of an elastoplastic constitutive model may supply more appropriate results than those from classical elastic models; its consideration is particularly meaningful in modelling the layer in which the major shear movements occur.
In the 2D model results, the distribution and intensity of the movements are fairly similar to those observed in the slope through monitoring data. In the $3 \mathrm{D}$ computations, the obtained displacements were, likewise, in good agreement with the in situ observed movement distribution; they were close in magnitude to the InSAR monitored data but were lower than medium-term GPS measurements.

The finite element simulations provide highly worthwhile information. In particular, the results obtained show that $(i)$ the movements are mainly due to the water pressure variation (a very close interaction between the meteorological events and the movements can be observed in the results), (ii) the active zones where infrastructures are damaged due to the movement are very limited in space and could be mitigated by drainage, and (iii) the increase in water pressure variation to simulate an extreme unfavourable case representing climate change extreme conditions does not cause a general instability. This final result shows that the risk of a sudden collapse of the slope is very low, even in the perspective of critical modifications caused by climate change.

Lastly, finite element modelling of the hydromechanical behaviour of the Triesenberg landslide constitutes a major contribution to the understanding of the hydrogeological and mechanical behaviour of the slope.

\section{Acknowledgments}

The authors wish to acknowledge the funding provided by the Office of Public Works (TBA) of the Principality of Liechtenstein for this complex investigation. Thanks are also due to our main partner, Dr. Riccardo Bernasconi, consulting geologist in Sargans (Switzerland), who actively participated in the collection and interpretation of field data and was very helpful in the preparation of the field investigation report. 


\section{References}

Bernasconi, R. 2002a. Tiefbauamt des Fürstentums Liechtenstein Hangsanierung Triesenberg - Hydrogeologische Überwachung Ergebnisse der Markierversuche Valünatal 1999/2000. Hydrogeologischer Bericht No. 1124-04.

Bernasconi, R. 2002b. Tiefbauamt des Fürstentums Liechtenstein Hangsanierung Triesenberg - Hydrogeologische Überwachung Messdaten 1999-2001. Hydrogeologischer Bericht No. 1124-03.

Bernasconi, R. 2003. Tiefbauamt des Fürstentums Liechtenstein Hangsanierung Triesenberg - Geophysikalische Messungen und Geologische Sondierungen. Hydrogeologischer Bericht No. 1124-02.

Biot, M.A. 1956. General solutions of the equations of elasticity and consolidation for a porous material. Journal of Applied Mechanics, 19: 91-96.

Colesanti, C., and Wasowski, J. 2004. Satellite SAR interferometry for wide-area slope hazard detection and site-specific monitoring of slow landslides. In Proceedings of the 9th International Symposium on Landslides, Rio de Janeiro, 28 June - 2 July 2004. Edited by W. Lacerda, M. Ehrlich, S.A.B. Fontoura, and A.S.F. Sayão. Taylor \& Francis, London. pp. 795-802.

Desai, C.S., Samtani, N.C., and Vulliet, L. 1995. Constitutive modelling and analyses of creeping slopes. Journal of Geotechnical Engineering, ASCE, 121(1): 43-56.

Dounias, G.T., Potts, D.M., and Vaughan, P.R. 1988. Finite element analyses of progressive failure: two case studies. Computers and Geotechnics, 6: 155-175.

DUTI. 1985. Projet d'école détection et utilisation des terrains instables. Final General Report, Ecole Polytechnique Fédérale de Lausanne (EPFL), Lausanne, Switzerland.

Eberhardt, E., Thuro, K., and Luginbuehl, M. 2005. Slope instability mechanisms in dipping interbedded conglomerates and weathered marls — the 1999 Rufi landslide, Switzerland. Engineering Geology, 77: 35-56.

EPFL. 2006. Lehrstühle für Ingenieur- und Umweltgeologie (GEOLEP) und für Bodenmechanik (LMS). Tiefbauamt des Fürstentums Liechtenstein. Geologische, hydrogeologische und geomechanizche Modellierung des Erdrutsches von Triesenberg (Fürstentum Liechtenstein), Abschlussbericht, Ecole Polytechnique Fédérale de Lausanne (EPFL), Lausanne, Switzerland.
Hillel, D. 1980. Fundamentals of soil physics. Academic Press, New York.

Jansson, P.-E., and Karlberg, L. 2001. Coupled heat and mass transfer model for soil-plant-atmosphere systems. Royal Institute of Technology, Department of Civil and Environmental Engineering, Stockholm.

Laloui, L., and Nuth, M. 2005. An introduction to the constitutive modelling of unsaturated soils. European Journal of Civil Engineering, 9(5-6): 651-670.

Laloui, L., Klubertanz, G., and Vulliet, L. 2003. Solid-liquid-air coupling in multiphase porous media. International Journal of Numerical and Analytical Methods in Geomechanics, 27(3): 183-206.

Roscoe, K.H., and Burland, J.B. 1968. On the generalized stressstrain behaviour of "wet" clay. In Engineering plasticity. Edited by J. Heyman and F.A. Leckie. Cambridge University Press, Cambridge, UK. pp. 535-609.

Schofield, A., and Worth, P. 1968. Critical state soil mechanics. McGraw-Hill, London.

Schrefler, B.A. 1984. The finite element method in soil consolidation (with applications to surface subsidence). Ph.D. thesis, University College of Swansea, Swansea, UK.

Tacher, L., Bonnard, Ch., Laloui, L., and Parriaux, A. 2005. Modelling the behaviour of a large landslide with respect to hydrogeological and geomechanical parameter heterogeneity. Landslides Journal, 2(1): 3-14.

Troncone, A. 2002. Numerical analysis of a landslide in soils with strain-softening behaviour. Géotechnique, 55(8): 585-596.

Tullen P. 2002. Méthodes d'analyse du fonctionnement hydrogéologique des versants instables. Ph.D. thesis, École Polytechnique Fédérale de Lausanne, Lausanne, Switzerland.

Van Eekelen, H.A.M. 1980. Isotropic yield surfaces in three dimensions for use in soil mechanics. International Journal of $\mathrm{Nu}-$ merical and Analytical Methods in Geomechanics, 4: 89-101.

Van Genuchten, M.T. 1980. A closed-form of the equation for predicting the hydraulic conductivity of unsaturated soils. Soil Science Society of America Journal, 44: 892-898.

Vulliet, L. 2000. Natural slopes in slow movement. In Modeling in geomechanics. Edited by M. Zaman, J.R. Booker, and G. Gioda. John Wiley \& Sons, Chichester, UK. pp. 654-676. 